\title{
Parallel ON and OFF Cone Bipolar Inputs Establish Spatially Coextensive Receptive Field Structure of Blue-Yellow Ganglion Cells in Primate Retina
}

\author{
Joanna D. Crook, ${ }^{1,3}$ Christopher M. Davenport, ${ }^{2,3}$ Beth B. Peterson, ${ }^{1}$ Orin S. Packer, ${ }^{1}$ Peter B. Detwiler, ${ }^{2}$ \\ and Dennis M. Dacey ${ }^{1,4}$ \\ Departments of ${ }^{1}$ Biological Structure and ${ }^{2}$ Physiology and Biophysics, and ${ }^{3}$ Neurobiology and Behavior Graduate Program, University of Washington, and \\ ${ }^{4}$ Washington National Primate Research Center, Seattle, Washington 98195
}

In the primate retina the small bistratified, "blue-yellow" color-opponent ganglion cell receives parallel ON-depolarizing and OFFhyperpolarizing inputs from short (S)-wavelength sensitive and combined long (L)- and middle (M)-wavelength sensitive cone photoreceptors, respectively. However, the synaptic pathways that create $S$ versus LM cone-opponent receptive field structure remain controversial. Here, we show in the macaque monkey retina in vitro that at photopic light levels, when an identified rod input is excluded, the small bistratified cell displays a spatially coextensive receptive field in which the S-ON-input is in spatial, temporal, and chromatic balance with the LM-OFF-input. ON pathway block with L-AP-4, the mGluR6 receptor agonist, abolished the S-ON response but spared the LM-OFF response. The isolated LM component showed a center-surround receptive field structure consistent with an input from OFFcenter, ON-surround "diffuse" cone bipolar cells. Increasing retinal buffering capacity with HEPES attenuated the LM-ON surround component, consistent with a non-GABAergic outer retina feedback mechanism for the bipolar surround. The GABAa/c receptor antagonist picrotoxin and the glycine receptor antagonist strychnine did not affect chromatic balance or the basic coextensive receptive field structure, suggesting that the LM-OFF field is not generated by an inner retinal inhibitory pathway. We conclude that the opponent S-ON and LM-OFF responses originate from the excitatory receptive field centers of S-ON and LM-OFF cone bipolar cells, and that the LM-OFFand $\mathrm{ON}$-surrounds of these parallel bipolar inputs largely cancel, explaining the small, spatially coextensive but spectrally antagonistic receptive field structure of the blue- $\mathrm{ON}$ ganglion cell.

\section{Introduction}

An early step in the neural coding for human color vision occurs when signals arising from long (L)-, middle (M)-, and short (S)wavelength sensitive cone photoreceptors interact antagonistically to create spectral opponency in retinal ganglion cells. Two classes of spectral opponent neurons have long been recognized: an $\mathrm{L}$ versus $\mathrm{M}$ cone or "red-green" pathway and an S versus combined L $+\mathrm{M}$ cone (LM) or blue-yellow pathway (Solomon and Lennie, 2007). However, the synaptic mechanisms that create cone opponency remain controversial. Wiesel and Hubel originally observed a receptive field in the lateral geniculate nucleus (LGN) that lacked center-surround organization but instead showed nearly spatially matched ON and OFF fields that differed in spectral tuning (Wiesel and Hubel, 1966) (see Fig.

Received March 12, 2009; revised May 18, 2009; accepted May 29, 2009.

This work was supported by the Paul Kayser International Award from the Retina Research Foundation (D.M.D.), the Human Frontier Science Program Grant RGP 00067/2004-C (P.B.D.), the National Primate Research Center at the University of Washington Grant RR00166, and National Institutes of Health Grants EY06678 (D.M.D.), EY01730 (Vision Research Core), EY02048 (P.B.D.), and GM07108 (C.M.D.). We thank Julian Vrieslander for programming assistance through the Vision Core and the development of the Vision Core Toolbox (http://vrc.biostr.washington.edu/index.html). We also thank John Troy and Barry Lee for advice and discussion and Toni Haun for technical assistance.

Correspondence should be addressed to Dennis M. Dacey, Department of Biological Structure, University of Washington, Seattle, WA 98195. E-mail: dmd@u.washington.edu.

D0I:10.1523/JNEUROSCI.1218-09.2009

Copyright $\odot 2009$ Society for Neuroscience $\quad$ 0270-6474/09/298372-16\$15.00/0
$1 A)$. This "coextensive" receptive field structure suggested a novel circuitry that sacrificed spatial opponency to transmit an unambiguous chromatic signal (De Monasterio and Gouras, 1975; de Monasterio, 1978b; Derrington et al., 1984; Reid and Shapley, 1992; Reid and Shapley, 2002; Solomon et al., 2005). Such a circuitry was suggested when the LGN-projecting, blueyellow pathway or blue-ON cell was shown to originate from a bistratified ganglion cell that extended dendrites in both the inner-ON and outer-OFF subdivisions of the inner plexiform layer (Rodieck, 1991; Dacey and Lee, 1994) (see Fig. 1B). Thus, coextensive, cone-opponent fields were hypothesized to arise by parallel excitatory S-ON and LM-OFF cone bipolar inputs to the small bistratified dendritic tree (Dacey, 1993, 1996; Dacey and Lee, 1994) (see Fig. 1C). Identification of synaptic inputs to the bistratified tree confirmed presumed S-ON bipolar and LM-OFF bipolar contacts with the inner and outer dendritic tiers, respectively (Calkins et al., 1998; Ghosh and Grünert, 1999). However, $\mathrm{L}-\mathrm{AP}-4$, the mGluR6 receptor agonist and selective ON pathway blocker, unexpectedly appeared to attenuate both the S-ON and LM-OFF responses (Dacey, 2000; Davenport, 2007; Field et al., 2007). These observations, together with recent anatomical (Schein et al., 2004) and physiological (Packer et al., 2007) evidence for LM surrounds in S cone photoreceptors and reports of center-surround receptive field structure in blue-ON cells (Field et al., 2007), suggested that S versus LM opponency arises not 
primarily postsynaptically by convergent $\mathrm{ON}$ and OFF bipolar inputs but presynaptically by horizontal cell to $S$ cone feedback. In such a center-surround model, the small bistratified cells might show both chromatic and spatially tuned achromatic response components (Gouras and Zrenner, 1979; Derrington and Lennie, 1984; Lennie and Movshon, 2005).

Recording from blue-ON cells in the macaque retina in vitro, we now show new evidence that the S-ON and LM-OFF fields are spatially well matched and that the LM-OFF response is spared after block of both the ON-pathway and/or GABAergic and glycinergic transmission, suggesting that neither ON-bipolar nor inhibitory pathways transmit the LM-OFF signal. ON pathway block unmasked an OFF-center/ON-surround structure for the LM field, consistent with input to the small bistratified cell from an OFF cone bipolar. We hypothesize that this LM-ON surround normally sums with an LM-OFF surround of the S-ON cone bipolar. The spatially coextensive blue-yellow receptive field can then be explained by summation of parallel excitatory inputs from S-ON center/LM-OFF surround "blue-cone" bipolar cells with LM-OFF center/LM-ON surround diffuse cone bipolar cells.

\section{Materials and Methods}

\section{Choroid-attached in vitro preparation}

Eyes from macaque monkeys (either $M$. nemestrina, $M$. fascicularis, or $M$. mulatta) were acquired through the tissue distribution program at the National Primate Research Center at the University of Washington. Eyes were removed at the time of kill under deep barbiturate anesthesia. After enucleation the anterior pole of the eye was removed, the vitreous drained, and the remaining eyecup placed in oxygenated Ames medium. The retina, choroid, and pigment epithelium were then dissected away from the sclera with care not to cause retinal detachment from the supporting layers. Radial cuts were made in the retina to create a flatmount that was adhered, ganglion cell layer up, to the glass bottom of a steel superfusion chamber that had been coated with poly-L-lysine (Sigma P1399, $10 \mathrm{mg}$ in $10 \mathrm{ml}$ of $\mathrm{H}_{2} \mathrm{O}$ ). The chamber was mounted on a steel heating element and four perfusion inlet tubes, a single outlet tube, an agar bridge, and a thermistor were inserted into the bath. The entire chamber assembly was mounted on the fixed stage of an upright microscope equipped with water-immersion optics (Nikon Eclipse E600FN). Visual stimuli were delivered to the photoreceptors from the vitreal or ganglion cell side of the retina as in situ, via the microscope objective lens as described further below. Superfusion rate was maintained at $18-20$ $\mathrm{ml} / \mathrm{min}$ by a peristaltic pump that recirculated a $3 \mathrm{~L}$ reservoir of Ames medium ( $\mathrm{pH} 7.37$; constant oxygenation with $95 \% \mathrm{O}_{2} / 5 \% \mathrm{CO}_{2}$ ); temperature was thermostatically maintained (Warner Instruments TC$344 \mathrm{~B}$ ) at $35-36^{\circ} \mathrm{C}$. Receptor agonists and antagonists (as described further below) were maintained in Ames medium in separate oxygenated reservoirs and could be introduced to the bath quickly by switching a solenoid valve at a common input to the chamber. In a limited number of experiments, retinal buffering was increased by adding $20 \mathrm{~mm}$ HEPES to the Ames medium, pH. 7.4; this increased the osmolarity of the solution from $\sim 280$ to $300 \mathrm{mOsm}$; in control experiments we substituted $20 \mathrm{~mm}$ sucrose for HEPES and found no effects of the small increase in osmolarity on the morphology or physiology of ganglion cells (Davenport et al., 2008).

\section{Electrophysiology}

Intracellular recordings were made from single ganglion cells using high impedance glass micropipettes ( $\sim 400 \mathrm{M} \Omega$; filled with $1 \mathrm{~m} \mathrm{~K}$ acetate; $1 \%$ neurobiotin and $0.5 \%$ pyranine). To target ganglion cells for intracellular penetration, the in vitro retina was stained with the dye acridine orange (several drops added to the superfusate in the chamber) which, as a fluorescent, basophilic dye stained the ganglion cell Nissl substance and under epifluorescent illumination permitted direct observation of ganglion cell bodies in vitro using a $40 \times$ water-immersion objective. Small bistratified cells were targeted by their distinct cell body size and shape relative to the more common midget and parasol ganglion cells. The identity of recorded cells was confirmed from their dendritic morphology after iontophoresis of pyranine (Fig. 1). Extracellular recordings were made with low impedance patch pipettes using the "loose-patch" method. The retinal surface was observed with a $60 \times$ water-immersion objective under infrared illumination on a video display using differential contrast optics. Patch pipettes were used to make a small hole in the inner limiting membrane at the retinal surface so as to expose a targeted ganglion cell body for intimate contact with the patch electrode. Small bistratified ganglion cells could be reliably identified based on fine details of soma morphology and size. Extracellular spikes were recorded in current or voltage clamp ( $0 \mathrm{mV}$ or $0 \mathrm{pA}$ holding potential). Data acquisition and stimulus presentation were coordinated by custom software running on an Apple Macintosh computer. Intracellular and extracellular recordings were amplified (Axon Instruments Axoprobe 2B; Axopatch 200B) and digitized (Instrutech ITC1600) at a sampling rate of $10 \mathrm{kHz}$. Response amplitude was measured as the first or second Fourier component of the averaged membrane potential or spike rate at the temporal frequency of stimulus modulation.

We include data from blue-ON cells that showed maintained activity in the range of 20 spikes/s (mean $\pm S D=22 \pm 13 ; n=19$ ). To quantitatively measure the maintained activity responses we recorded the activity of 19 cells to a mean background (S:L:M = 1:1:1) for $\sim 5 \mathrm{~s}$. Otherwise maintained activity was judged qualitatively by ear when obtaining and throughout a recording. We found a good correlation between maintained discharge and the overall sensitivity of a cell to our subsequent stimulus sets. In some cells in which maintained activity was low or absent we found reduced sensitivity to low contrast stimuli. Such reduced sensitivity tended to correlate with retinal detachment from the choroid-retinal pigment epithelium (RPE) and we did not further collect or include data from these cells.

\section{Stimulus generation}

Projection and control of stimulus primaries. Spatial stimuli at lower temporal frequencies were generated by a stimulus generator (VSG5, Cambridge Research Systems) input to a digital light projector (DLP) (VistaGRAPHX 2500, Christie Digital). Full-field stimuli at higher temporal frequencies were generated by a light emitting diode (LED) based stimulator (Pokorny et al., 2004). Stimuli were focused on the retina through a $4 \times$ objective for intracellular recording and a $10 \times$ objective for loose patch recordings.

The LM and S cone inputs to ganglion cells were measured by modulating the light output of the stimulator primaries. The irradiances of the primary spectra were measured with a PR705 spectroradiometer (Photo Research). The peak wavelengths and integrated photon fluxes of the red cyan, and blue LED primary spectra (Fig. $2 \mathrm{~A}$ ) were 660, 514, and $457 \mathrm{~nm}$ and $7.0 \times 10^{7}, 1.6 \times 10^{7}$, and $2.5 \times 10^{7}$ photons $/ \mathrm{s} / \mu \mathrm{m}^{2}$, respectively. The peak wavelengths and integrated photon fluxes of the red, green, and blue primaries of the DLP stimulator (Fig. $2 B$ ) were 636,550 , and $465 \mathrm{~nm}$ and $2.7 \times 10^{6}, 6.9 \times 10^{5}$, and $1.8 \times 10^{5}$ photons $/ \mathrm{s} / \mu \mathrm{m}^{2}$, respectively.

To quantitatively predict the effectiveness of the light delivered by each primary to the cone aperture, we calculated the products of each primary irradiance spectrum and each cone spectral sensitivity function. The sensitivity functions (Baylor et al., 1987) were corrected for the spectrally broadening effects of self-screening by assuming an outer segment length of $5 \mu \mathrm{m}$ and a pigment density of $0.016 / \mu \mathrm{m}$. Each product was then summed across wavelength. The resulting nine numbers have units of effective photons $/ \mathrm{s} / \mu \mathrm{m}^{2}$ and represent irradiance corrected by cone spectral sensitivity. Effective photons $/ \mathrm{s} / \mu \mathrm{m}^{2}$ was then converted to photoisomerizations/s/cone by multiplying by the area of the cone aperture. In previous studies involving transverse illumination of the cone outer segment where funneling of the inner segments plays no role, the conversion factor commonly used is $0.37 \mu \mathrm{m}^{2}$ (Baylor et al., 1979). The efficiency of photoisomerization (0.67) (Dartnall, 1972) is included in this value. In our retinal preparation (see above), as in vivo, light is incident on the vitreal surface of the retina. Photoreceptor quantal catch thus depends on the axial illumination of the cone, as well as the funneling of the cone inner segment. Funneling by the inner segment has been estimated to increase the effective area of the peripheral inner segment 
A
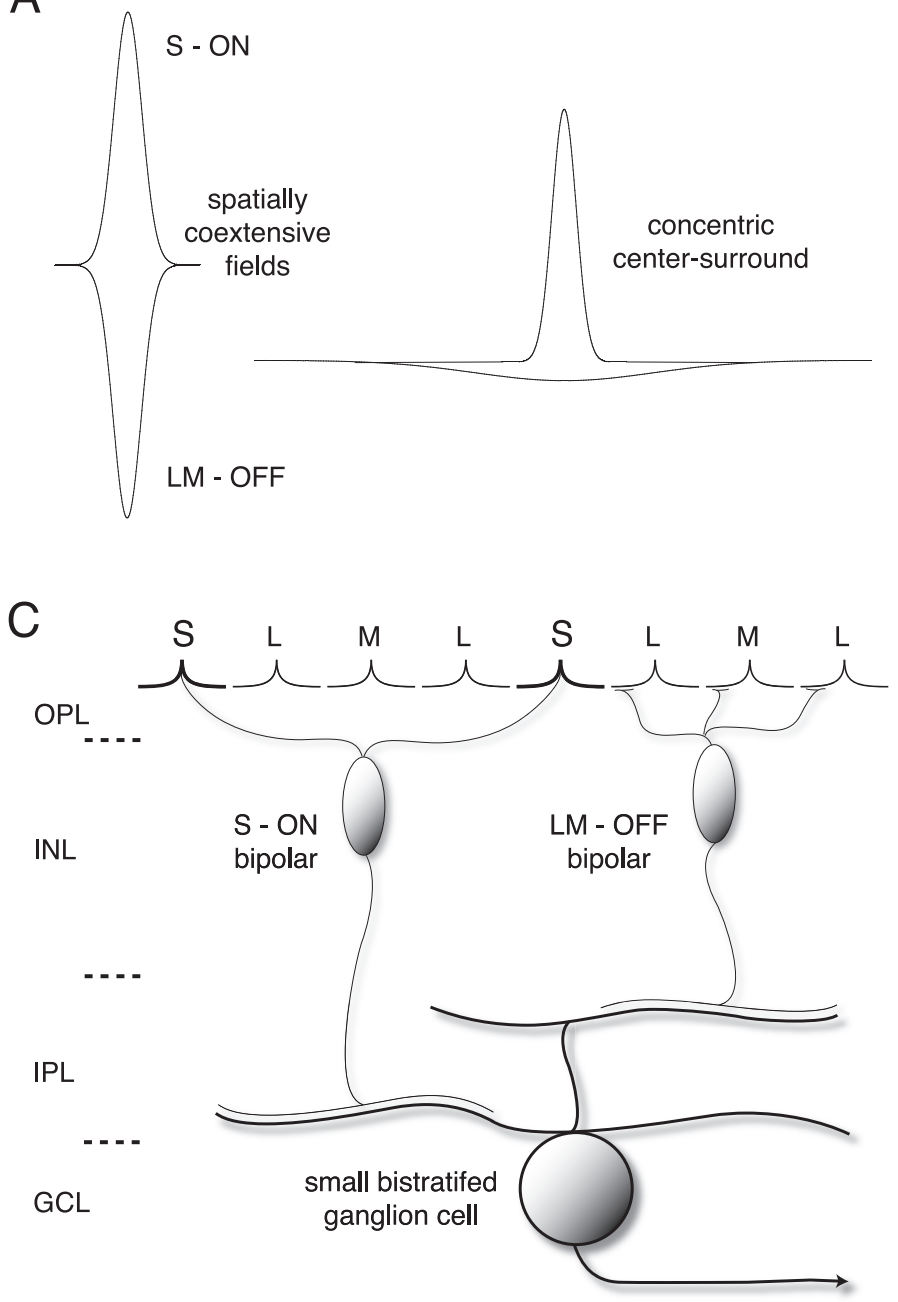

B
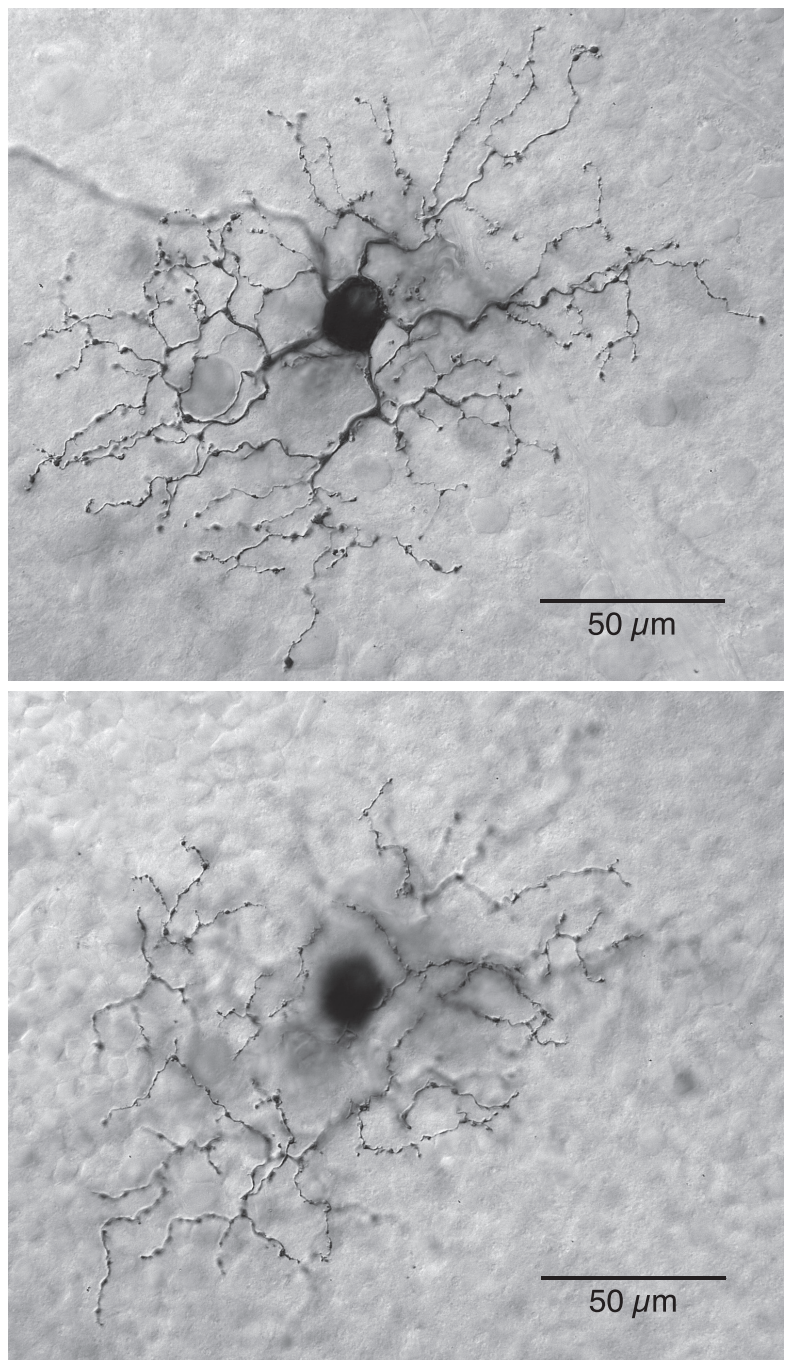

Figure 1. Proposed receptive field structure and cone bipolar inputs to the small bistratified blue-ON cell type in the macaque monkey retina. $A$, A typical concentric center-surround receptive field spatial profile plotted (right) as two Gaussian functions, a narrow center with high peak sensitivity and a broad surround with low peak sensitivity, is compared with a coextensive receptive field profile (left) marked by two narrow antagonistic fields that show comparable spatial extents and sensitivity profiles. Here and throughout the study the positive and negative Gaussian profiles indicate $\mathrm{ON}$ and $\mathrm{OFF}$ responses, respectively. $\boldsymbol{B}$, The bistratified dendritic tree of the blue- $\mathrm{ON}$ cell (whole mount; neurobiotin intracellular fill; $3 \mathrm{~mm}$ retinal eccentricity) with separate arbors in inner-ON (top; plane of focus near ganglion cell layer) and outer-OFF (bottom; plane of focus near amacrine cell layer) portion of the IPL led to the hypothesis that parallel ON and OFF cone bipolar input to the dendritic tree could underlie spatially coextensive S ON versus LM OFF cone opponency. C, Schema illustrating known cone bipolar input to the bistratified dendritic tree of the blue-ON cell that could support coextensive $S$ cone versus LM cone receptive field structure.

aperture by at least a factor of 3 (Packer et al., 1996). Thus, for our whole-mount in vitro preparation, we consider the use of $0.37 \mu \mathrm{m}^{2}$ as a very conservative estimate of cone aperture to make the conversion to photoisomerizations/s/cone.

Often, the intensity of stimuli used in human visual psychophysics or in physiological experiments in the intact primate eye are expressed in units of retinal illuminance, or Trolands (Td). To aid comparison with our data, we calculated that for a peripheral cone with an inner segment aperture of $9 \mu \mathrm{m}, 1$ Troland (Td) was equivalent to $\sim 30$ photoisomerizations/s/cone. For a rod with an inner segment aperture of $2.5 \mu \mathrm{m}, 1$ scotopic troland was equivalent to $\sim 4$ photoisomerizations $/ \mathrm{s} / \mathrm{rod}$.

Construction of cone-type selective stimuli. Cone-isolating stimuli (Fig. $2 E, F$ ) were obtained by the method of silent substitution (Estévez and Spekreijse, 1974, 1982) and were based on the cone absorption spectra and the stimulator primary spectra detailed above. The intensities of three primary lights were modulated and their relative irradiances adjusted (Fig. $2 C, D$ ) so that quantal catch in a subset of the cone types was modulated in isolation. To modulate the $\mathrm{L}$ and $\mathrm{M}$ cones equally but not the $S$ cones (Fig. $2 C$, right; $D$, right), the red and green primaries were modulated with means and amplitudes chosen to create equivalent mod- ulation depths (cone contrast) in both cone types. A small counter modulation of the blue primary was used to offset the effects of the red and green primaries on the $S$ cone. The primary means and amplitudes used to selectively stimulate $\mathrm{S}$ cone inputs followed the opposite pattern (Fig. $2 C$, left; $D$, left). Modulation of the short wavelength primary effectively modulated $\mathrm{S}$ cones, whereas counter modulations of the long and middle wavelength primaries offset the effect of the blue primary on the $\mathrm{L}$ and $\mathrm{M}$ cones. The primary LED and DLP stimuli shown in Figure 2, $E$ and $F$, were calculated to give cone contrasts (amplitude/mean) of $48 \%$ and $16 \%$, respectively, around a matched mean quantal catch for all three cone types. (LM) $-\mathrm{S}$ and LMS cone-isolating stimuli were generated using the same principles. All stimuli were presented as a $2000 \mu \mathrm{m}$ diameter spot whose intensity was sinusoidally modulated at a temporal frequency of $2 \mathrm{~Hz}$. For the intracellular recordings, cone-isolating stimuli were generated as outlined above but a much higher cone contrast $(\sim 80 \%)$ was achieved by modulating around a mean quantal catch that differed for each cone type (L:M:S = 9:7:1) (see Figs. $2 G, 7 A, B$ ).

Estimating cone synaptic weights. To determine the relative strengths of the $S$ and LM cone inputs to a blue-ON cell's receptive field, we systematically varied the sign and depth of S and LM cone modulation while 
A

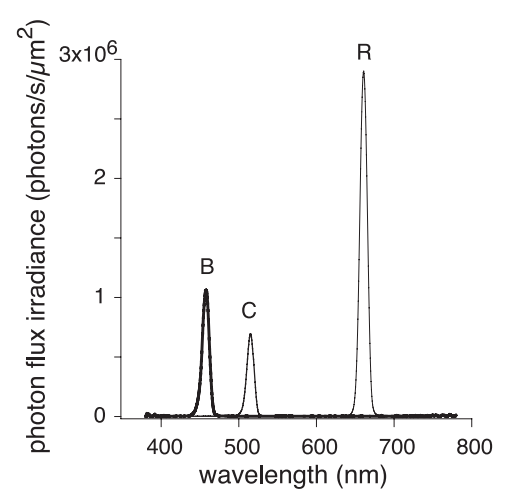

C

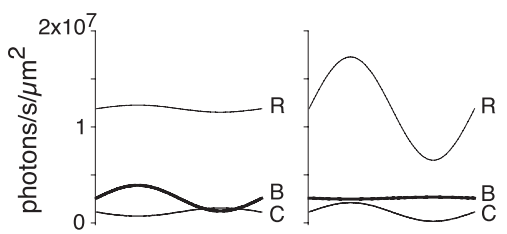

E

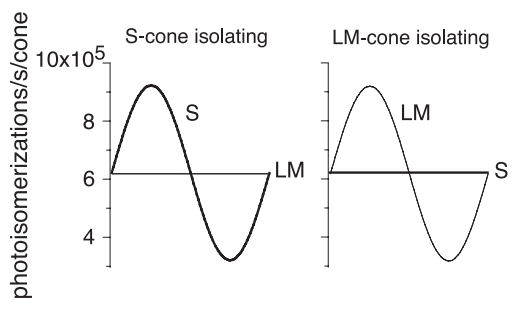

$\mathrm{B}$

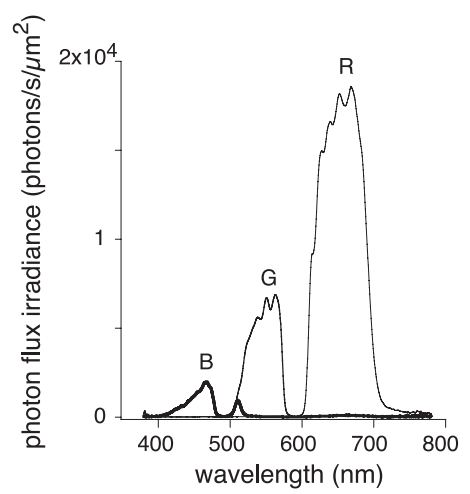

D

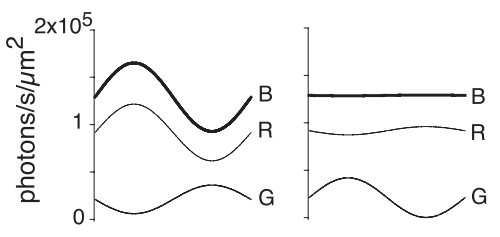

F

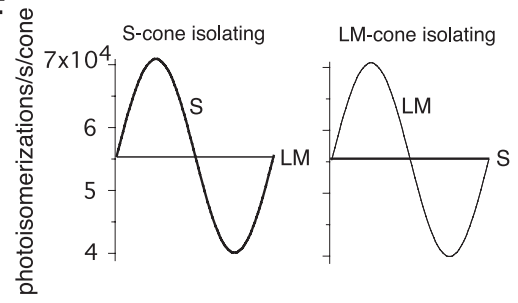

G

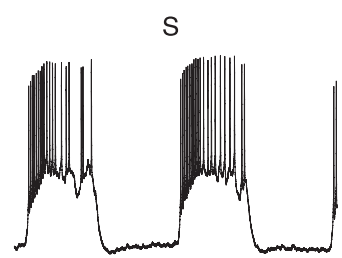

LM

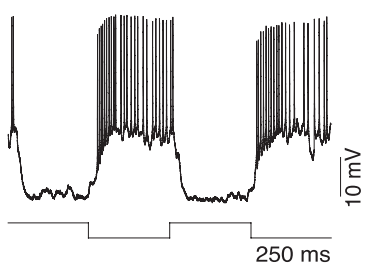

$\mathrm{H}$

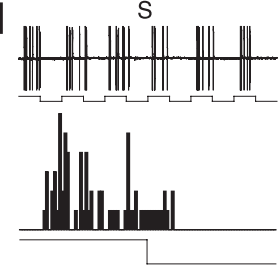

LM
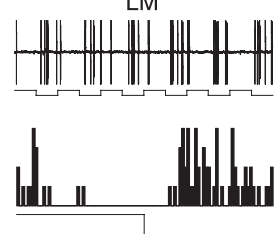

Figure 2. Blue-ON cells had ON responses to $S$ cone-isolating stimuli and OFF responses to LM cone-isolating stimuli. Coneisolating stimuli were made by differentially modulating and combining the outputs of red, cyan and blue LEDs or red, green and blue DLP primaries. $\boldsymbol{A}, \boldsymbol{B}$, Calibrated spectra for red, cyan and blue LEDs $(\boldsymbol{A})$ and red, blue and green DLP primaries $(\boldsymbol{B}) . \boldsymbol{C}, \boldsymbol{D}$, Predicted intensity and phase of each LED ( $\boldsymbol{C}$ and DLP $(\boldsymbol{D})$ channel, using $\mathrm{L}, \mathrm{M}$, and $\mathrm{S}$ cone spectral sensitivities (Baylor et al., 1987) to isolate $S$ and $L M$ cones around a mean equal cone contrast background. $E, F$, Predicted $S$ and $L M$ photoisomerizations $/ \mathrm{s} /$ cone to the stimuli presented in $\boldsymbol{C}$ and $\boldsymbol{D}$, respectively. Maximum contrast for $S$ and $L M$ cone-isolating stimuli achieved was $48 \%$ with the LEDs and $36 \%$ with the DLP primaries. G, Intracellular responses to high contrast (79\%) S (top) and LM cone (bottom) isolating square wave stimuli $(2 \mathrm{~Hz})$. $\boldsymbol{H}$, Voltage responses (top) and spike histograms (bottom) from extracellular loose patch recordings to square wave $(2 \mathrm{~Hz})$ cone-isolating stimuli that modulated $\mathrm{S}$ and $\mathrm{LM}$ cones either in isolation $(\mathrm{S}$ or $\mathrm{LM})$, in phase (LMS), or in counterphase $(L M-S)$, the negative sign indicating a contrast decrement for the $S$ cone. Stimulus contrast for each cone was $16 \%$ (for increments and decrements), presented on a background in which the mean photoisomerizations were equal for all three cone types.

holding mean quantal catch equal for all three cone types (see Fig. 4A). Underlying this stimulus design is the assumption that, at low to moderate contrasts under conditions of equivalent adaptation states across cone types, inputs from different cone types contribute linearly to the response of the cell. If this assumption is true, it should be possible to fit

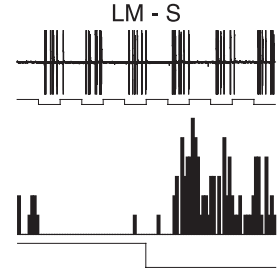

LMS
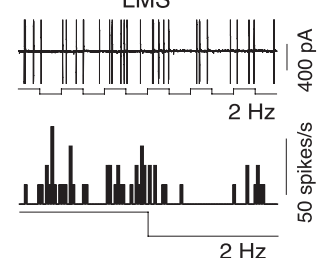

the response with a simple linear model relating calculated cone contrast to response amplitude. This model has been described in detail previously and used to measure the relative weights of synaptic input to the $\mathrm{H} 1$ horizontal cells and the midget and parasol ganglion cells (Dacey et al., 2000a; Diller et al., 2004).

The amplitude of the sinusoidal modulation of each primary was chosen to create a set of 13 stimuli whose $S$ and LM contrasts are varied systematically (see Fig. 4A). Initially, S and LM cone contrast are equal and of the same sign. $S$ cone contrast is then reduced to zero in a stepwise manner while LM cone contrast is increased to a peak (LM cone isolation). S cone contrast then is reversed in sign (equivalent to a 180 degree phase shift) and is increased until LM and $S$ contrast are equal and in antiphase $(\mathrm{LM}-\mathrm{S})$. LM contrast is then reduced to zero while $\mathrm{S}$ cone contrast peaks (S cone isolation). Finally, the two cone contrasts are returned to the same sign and in the last stimulus are again of equal contrast. For a cell that received equally weighted LM OFF and S ON inputs (see Fig. $4 B$ ), a response null would occur when LM and $S$ cones are stimulated equally and in the same phase (see Fig. $4 B$, first and last points) and a peak response when LM and $S$ cone contrasts are equal and opposite in phase (see Fig. $4 B$, point 7 ). If the $S$ input dominated, the peak response would occur at point $>7$ or vice versa. The relative strengths were calculated by fitting the responses with a weighted sum of S and LM cone inputs to determine the peak: response amplitude $=W_{\mathrm{S}} C_{\mathrm{S}}+W_{(\mathrm{LM})} C_{(\mathrm{LM})}$, where $W_{\mathrm{S}}$ and $W_{(\mathrm{LM})}$ are the weights of the cone inputs, and $C_{\mathrm{S}}$ and $C_{(\mathrm{LM})}$ are the contrasts of the stimulus.

Finally, this model predicts that the phase of an opponent response would be constant, whereas the phases of LM and S nonopponent responses would show a 180 degree phase shift at the stimulus whose contrast ratio produced a response minimum.

Spatial stimuli and receptive field model. The S and LM components of the blue-ON receptive field were mapped using cone-isolating drifting-sinusoidal gratings of increasing spatial frequency, spots of increasing diameter, or annuli of increasing inner diameter. To center the stimulus on the cell's receptive field, the cell body was first placed in the middle of the stimulus field. Horizontal and vertical fine diameter slits ( 10 or $25 \mu \mathrm{m}$ width) were then systemically moved to further locate the most sensitive point in the receptive field. The location of the peak response was defined to be the receptive field center; stimuli were positioned relative to this point. In cases where intracellular dye filling was coupled with receptive field mapping, this point typically corresponded to the approximate center of a circle encompassing both the inner and outer dendritic tiers of the bistratified tree. Stimuli were modulated at a temporal frequency of 2 or $4 \mathrm{~Hz}$. Contrast $\left(L_{\mathrm{MAX}}-L_{\mathrm{MIN}}\right) /$ $\left(L_{\mathrm{MAX}}+L_{\mathrm{MIN}}\right)$ of gratings, spots and annuli was set to $28 \%$ or $36 \%$ and was modulated around a mean level that equated the quantal catch for all three cone types. The first Fourier (F1) components of the harmonic responses were averaged over 8 or 12 stimulus repetitions and fit with a 
Gaussian or a Difference of Gaussians (DOG) receptive field model that incorporates both the amplitude and phase of the neural response (Enroth-Cugell et al., 1983), as described in detail previously (Dacey et al., 2000b). In brief, the receptive field center had a radial profile $C(r)$, as follows:

$$
C(r)=W_{\mathrm{c}} \cdot \frac{1}{\pi} \cdot\left(\frac{1}{R_{\mathrm{c}}}\right)^{2} \cdot e^{\left(-r / R_{\mathrm{c}}\right)^{2}},
$$

where $W_{\mathrm{c}}$ is the gain of the center and $R_{\mathrm{c}}$ is the radius of the center (where sensitivity has fallen to $1 / \mathrm{e}$ of its peak). The amplitude of responses to stimulus modulation was computed as the two-dimensional integral of the product of the receptive field and stimulus profiles. Control responses to $S$ and LM gratings were fit with only a center, responses to LM gratings in the presence of L-AP-4 were fit with a center and a surround $S(r)$, with gain $W_{\mathrm{s}}$ and radius $R_{\mathrm{s}}$. The overall amplitude and phase of the responses were computed by combining the center, and if appropriate, the surround responses with the following equation:

$$
R=\left(A_{\mathrm{c}} \cdot e^{\left(i \cdot \theta_{\mathrm{c}}\right)}\right)+\left(A_{\mathrm{s}} \cdot e^{\left(i \cdot \theta_{\mathrm{s}}\right)}\right),
$$

where $A_{\mathrm{c}}$ and $A_{\mathrm{s}}$ are the amplitudes of center and surround responses and $\theta_{c}$ and $\theta_{s}$ are the phases of their responses at the temporal frequency of the stimulus modulation. Initial fitting parameters were manually set, and numerical search was used to minimize the mean square difference between the measured and predicted responses.

Contrast response functions. The contrast sensitivity and gain values for the blue-ON cell's S and LM inputs and for parasol cells' LM inputs (parasol cells did not respond to the $\mathrm{S}$ cone-isolating stimuli) were measured and calculated using the same cone-isolating stimuli described above with gratings of optimal spatial and temporal frequency. The gratings were presented at contrasts ranging from 2 to $28 \%$ or from 2 to $38 \%$ depending on the background light level. The blue-ON cell's $S$ and LM contrast response functions were fit with a line by least-squares regression of which the slope indicated the contrast gain. The parasol cells contrast response functions were fit with a Naka-Rushton saturation function: $Y=a x /(b+x)$, where $a$ is the maximal response in impulses per second; $x$ the Michelson contrast; and $b$ the semisaturation constant (the contrast at which response amplitude is half the maximal response). Such curves are characterized by their percentage contrast gain, $a / b$.

Temporal modulation. The temporal sensitivities and latencies of the $S$ and LM components of the receptive field were characterized using the LED stimulator. Full-field cone-isolating stimuli were sinusoidally modulated at temporal frequencies ranging from 0.61 to $78 \mathrm{~Hz}$. The contrast was set to $24 \%$ or $48 \%$. The mean light level equated the quantal catch for all three cone types. Responses were averaged for $4 \mathrm{~s}$ at each temporal frequency. The F1 phase was found to be an approximately linear function of the temporal frequency and its slope (cycles/Hz) was used as a measure of the cell's visual latency (Frishman et al., 1987).

Pharmacology. The circuitry underlying the receptive field of the blue-ON ganglion cell was investigated with pharmacological agents. The role of inner retinal inhibition was investigated with the glycine receptor antagonist strychnine $(1 \mu \mathrm{M}, \mathrm{S} 8753$, Sigma $)$ and the $\mathrm{GABA}_{\mathrm{A} / \mathrm{C}}$ receptor antagonist picrotoxin (200 $\mu \mathrm{M}, \mathrm{P} 1675-1 \mathrm{G}$, Sigma). The role of outer retinal inhibition was tested by adding the $\mathrm{pH}$ buffer HEPES (20 $\mathrm{mm}, \mathrm{H7523}$, Sigma) to Ames with the $\mathrm{pH}$ adjusted to 7.4. The metabotropic glutamate receptor agonist, L-AP-4 (100 $\mu \mathrm{M}, \mathrm{A} 1910$, Sigma) was used to block the ON pathway at the photoreceptor-bipolar synapse. All pharmacological agents were dissolved in Ames medium and applied to the entire retina by continuous superfusion. We waited $\sim 4 \mathrm{~min}$ for full drug effect and typically recorded for $\sim 30 \mathrm{~min}$ before wash out (Crook et al., 2008).

\section{Results}

\section{Targeting small bistratified blue-ON cells}

Small bistratified, blue-ON cells were targeted in vitro by their relatively large cell bodies comparable to that of the parasol ganglion cells (Dacey, 1993; Dacey et al., 1994) observed either by epiillumination after vital staining with acridine orange or by infrared illumination of the unstained retina. Blue-ON cells were easily distinguished from parasol cells by sustained OFF responses to $500 \mathrm{~ms}$ light steps using the red or green LED primary and sustained ON responses to the blue LED primary. Parasol cells and other nonopponent cell types (Crook et al., 2008) showed transient responses that varied in amplitude but did not change in sign in response to the LED primary lights. A large bistratified blue-ON cell (Dacey and Packer, 2003) would have had responses similar to a small bistratified blue-ON, but these cells show smaller cell body size and have significantly larger receptive fields than those mapped for the small bistratified blue-ON cells. Altogether, we include data collected from 89 blue-ON cell recordings. For a subset of these cells we mapped S and LM receptive fields, compared S and LM sensitivity, and ran a series of pharmacology experiments. The effect of the inhibitory receptor antagonists, picrotoxin and strychnine, was tested on 17 cells, L-AP-4 was tested on 22 cells either alone or in combination with the inhibitory antagonists, and for 3 cells that had been tested with picrotoxin, strychnine, and L-AP4, HEPES was also applied. Rod inputs were characterized in an additional 16 cells. Finally, data from cells recorded intracellularly $(n=6)$ were also included.

\section{Identification of a rod-mediated $\mathrm{ON}$ input to blue-ON cells}

One of the main goals of this study was to measure the relative weights and spatial dimensions of S-ON and LM-OFF input to the small bistratified blue-ON cell. However, the stimuli used to isolate the S versus LM cone inputs described in Materials and Methods can also provide strong stimulation of rods. Conflicting reports describe a distinctive excitatory rod input (Virsu et al., 1987) or an apparent lack of rod input for cells of the blue-ON pathway (Lee et al., 1997). At the start of an experiment, the macaque in vitro preparation was maintained in a dark adapted state and when first recording from a blue-ON cell, we often observed strong $\mathrm{ON}$ responses to both $\mathrm{S}$ and LM cone-isolating stimuli in identified small bistratified cells at retinal illuminances ( $<10$ photoisomerizations/cone/s) below the threshold for conemediated responses in our preparation (Dacey et al., 2005). Since additivity of rod and cone signals at mesopic levels in ganglion cells has been well documented (Gouras and Link, 1966; Gouras, 1967; Enroth-Cugell et al., 1977; Lee et al., 1997), it thus became critical to provide a preliminary characterization of this apparent rod input and, crucially, to determine the illuminance at which rod signals in our in vitro preparation could potentially interact with and effect our measurement of cone signal properties. The response of a blue-ON cell to a $1500 \mathrm{~ms}$ blue or green primary LED light step shows a dramatic change in temporal response, as a transition is made from cone-dominated to a rod-dominated response over a $4 \log$ unit illuminance range (Fig. $3 A$ ) that spans the mesopic level ( $\sim 0-3 \log _{10}$ photopic trolands). At medium to high photopic levels $\left(\sim 10^{3}-10^{5}\right.$ photoisomerizations/cone/s), a sustained $\mathrm{ON}$ response to the blue primary and an OFF response to the green primary are observed and these responses are presumably driven primarily by an S-ON response to the blue and an LM-OFF response to the green primary (Fig. $3 A$, top traces). Latency from blue stimulus onset (or green stimulus offset) to first spike is $\sim 40-60 \mathrm{~ms}$ (Fig. $3 B$, top traces). As retinal illuminance is reduced, however, from $\sim 10^{4}$ to 10 photoisomerizations/cone/s, the OFF response to the green primary is replaced by an ON response $(n=16)$. Thus, at $\sim 15-150$ photoisomerizations/cone/s, both the blue and green stimuli elicit similar, sustained $\mathrm{ON}$ responses (Fig. $3 \mathrm{~A}$, bottom traces). At this light level, the rod quantal catch dominates and the latency from stimulus 
A

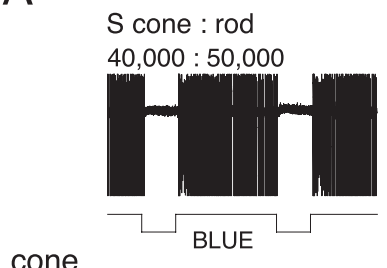

cone
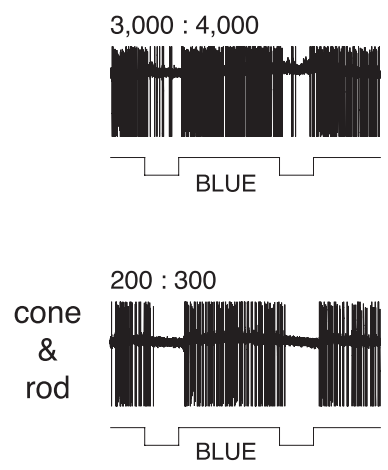

rod
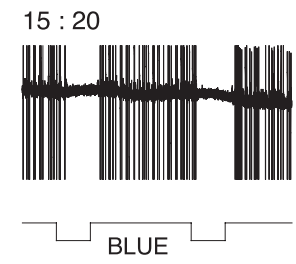
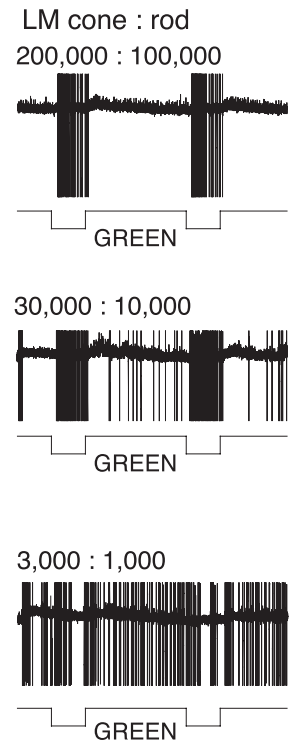

$150: 70$

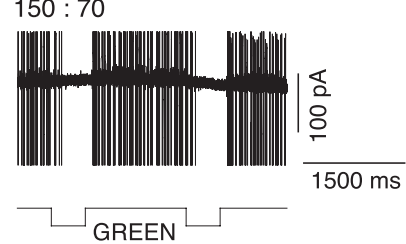

B
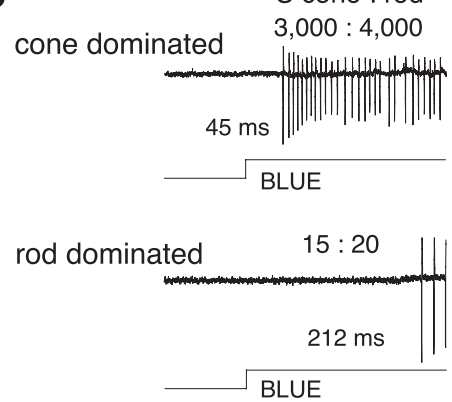

C
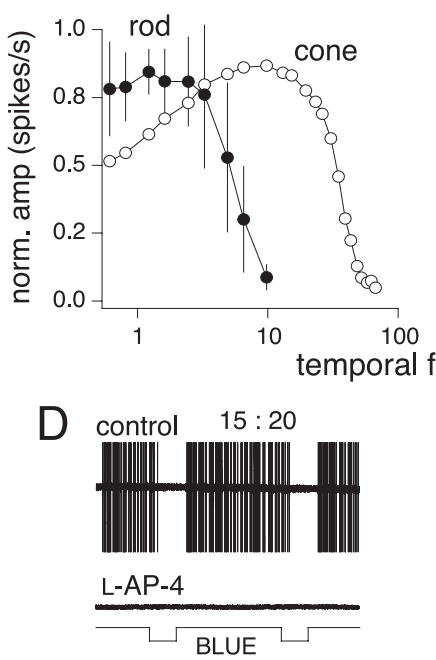

LM cone : rod $30,000: 10,000$
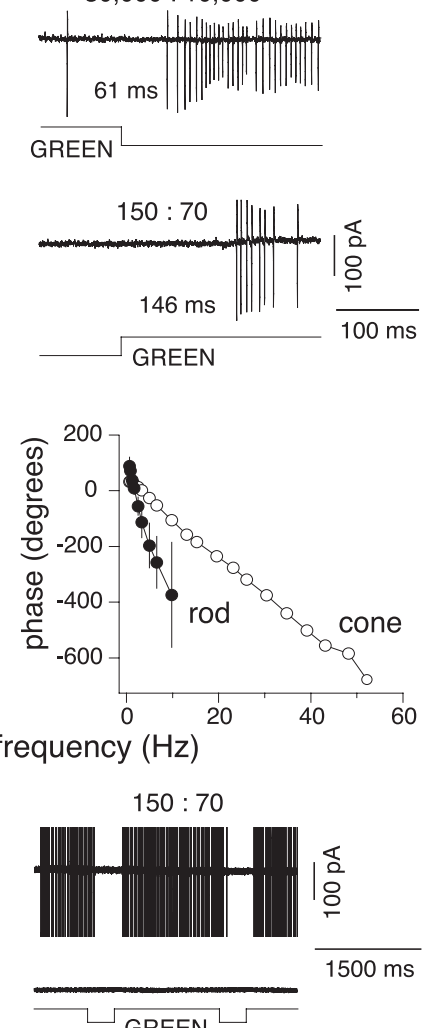

Figure 3. Blue-ON cells have rod-ON responses at low retinal illuminances. $A$, Blue-ON responses to $1500 \mathrm{~ms}$ blue and green primary LED light steps measured across a 4 log unit illuminance range with the integrated irradiance (photons $/ \mathrm{s} / \mu \mathrm{m}^{2}$ ) of the blue primary LED light decreasing from $1.8 \times 10^{5}$ to $1.7 \times 10^{4}$ to $1.4 \times 10^{3}$ to $9.4 \times 10^{1}$ photons $/ \mathrm{s} / \mu \mathrm{m}^{2}$ (top to bottom) and the green primary LED light from $6.9 \times 10^{5}$ to $8.1 \times 10^{4}$ to $8.5 \times 10^{3}$ to $5.3 \times 10^{2}$ photons $/ \mathrm{s} / \mu \mathrm{m}^{2}$ (top to bottom). The number of photoisomerizations/s/cone for the blue and green primary LEDs at each light level was calculated for $S$ cone:rod (left) and LM cones:rod (right), respectively, and are indicated above each trace. $B$, Rod-ON responses were at least twice as slow as cone-ON responses to the blue primary LED (left) and to cone OFF responses to the green primary LED (right). The time (in milliseconds) to the first spike after the onset or decrement of the primary LED is indicated for each trace. The number of photoisomerizations/s/cone of S cone:rod (left) and LM cones:rod (right) for the blue and green primary LEDs, respectively, are indicated above each trace. C, The small bistratified cells rod-ON responses (solid circles) do not respond to modulation $>10 \mathrm{~Hz}$, whereas S-ON responses at high photopic light levels (open circles) respond to much higher temporal frequencies (see Fig. 5 for responses to $S$ cone-isolating stimuli). Plots show the normalized average $0 \mathrm{~N}$-rod response (left) and phase (right) to $100 \%$ contrast sine waves modulated at different temporal frequencies; error bars indicate SD $(n=10)$. The response latency calculated from the phase was $\sim 5$ times slower $(177 \pm 36 \mathrm{~ms}$, mean $\pm S D ; n=10)$ than cone latencies ( $40 \pm 3 \mathrm{ms,}$ mean $\pm S D ; n=20$ ) as calculated for S cone-isolating stimuli at photopic light levels (see Fig. $5 D$ ). $\boldsymbol{D}$, Rod ON responses measured at low retinal illuminances to both the blue and green LED primaries were eliminated with bath application of L-AP4, the mGluR6 receptor agonist. Photoisomerizations indicated as in $\boldsymbol{A}$ and $\boldsymbol{B}$.

onset to spike threshold increases to $\sim 150-200 \mathrm{~ms}$ (Fig. 3B, bottom traces). At intermediate illuminances (Fig. $3 \mathrm{~A}$, middle traces; $10^{2}-10^{3}$ photoisomerizations/cone/s), the rod-ON and LM-OFF responses are not easily distinguished and there appears to be some mixing of the two signals. The large latency difference between the rod- and cone-dominated responses was also manifest in the temporal frequency response to sinusoidal modulation at high versus low retinal illuminances (Fig. 3C). At low illuminances, the rod mediated response peaked at $2 \mathrm{~Hz}$, rolling off sharply between 4 and $7 \mathrm{~Hz}$ compared with the cone mediated response peak at $\sim 10 \mathrm{~Hz}$, rolling off between 40 and $50 \mathrm{~Hz}$. Response latency derived from linear fits to response phase was $\sim 5$ times slower $(177 \pm 36 \mathrm{~ms}$, mean $\pm \mathrm{SD} ; n=10)$ than cone latencies ( $40 \pm 3 \mathrm{~ms}$, mean $\pm \mathrm{SD} ; n=20)$. Finally, at the low retinal illuminances eliciting a sustained $\mathrm{ON}$ response to both the blue and green LED primaries, bath application of L-AP4, the mGluR6 receptor agonist, completely eliminated the ON light response $(n=2)$, consistent with an origin of this signal from the depolarizing rod bipolar cell (Fig. 3D). These results provide evidence for a strong rod-mediated ON input to the small bistratified blue-ON cells. Below cone threshold, the light response is converted from an S-ON, LM-OFF response to a rod-ON re- sponse. From cone threshold to rod saturation (between $10^{2}$ and $10^{3}$ photoisomerizations/cone/s), there is potential for interaction of the rod-ON input with the $\mathrm{S}$ and LM cone inputs. Given the large difference between the rod and cone signal dynamics, the nature of this interaction would be dependent on the stimulus temporal frequency as well as the illuminance level. At $10^{4}$ photoisomerizations/cone/s and above we assume rods are in saturation; we believe this is a safe assumption as psychophysical experiments show that saturation of primate scotopic vision begins when a background light reaches $\sim 100$ scotopic trolands (Hayhoe et al., 1976); this is $\sim 400$ photoisomerizations/cone/s, and is consistent with recordings from individual primate rods (Baylor et al., 1984). We have used stimuli well above this level for all subsequent measurements of cone responses in the small bistratified blue-ON cells.

Weighting of S-ON versus LM-OFF input to the blue-ON cells The balance and linearity of S ON versus LM OFF inputs to the blue-ON cell was assessed with two different protocols. As a first rough test, cone-isolating pulses were modulated at $16 \%$ contrast in the following combinations; $\mathrm{S}, \mathrm{L}+\mathrm{M}$ (LM), $\mathrm{L}+\mathrm{M}+\mathrm{S}$ (LMS) and $\mathrm{LM}-\mathrm{S}$, the negative sign indicating a $16 \%$ contrast decre- 
Table 1. Summary of effects of GABAa/c and glycine receptor antagonists on the chromatic responses properties of the blue-0N cell

\begin{tabular}{llllll}
\hline & $\begin{array}{l}\text { S:LM pulse responses } \\
\text { (spikes/s) }\end{array}$ & $\begin{array}{l}(\mathrm{LM}-\mathrm{S}):(S)+(\mathrm{LM}) \text { pulse responses } \\
(\text { spikes/s) }\end{array}$ & $\begin{array}{l}\text { S:LM cone input } \\
\text { weights }\end{array}$ & $\begin{array}{l}\text { S:LM radius at 1SD } \\
(\mu \mathrm{m})\end{array}$ & $\begin{array}{l}\text { S:LM integrated } \\
\text { volume }\end{array}$ \\
\hline Control & $1.16 \pm 0.24(n=67)$ & $0.86 \pm 0.14(n=67)$ & $1.09 \pm 0.21(n=51)$ & $0.92 \pm 0.13(n=55)$ & $1.15 \pm 0.31(n=55)$ \\
Picrotoxin & $1.11 \pm 0.25(n=7)$ & $1.05 \pm 0.13(n=7)$ & $1.00 \pm 0.30(n=10)$ & $1.00 \pm 0.19(n=3)$ & $1.19 \pm 0.02(n=3)$ \\
Strychnine & $1.07 \pm 0.19(n=9)$ & $1.02 \pm 0.17(n=9)$ & $1.10 \pm 0.20(n=6)$ & $0.93 \pm 0.31(n=3)$ & $1.05 \pm 0.18(n=3)$ \\
Picrotoxin and strychnine & $1.08 \pm 0.25(n=7)$ & $1.03 \pm 0.22(n=7)$ & $1.07 \pm 0.16(n=5)$ & $0.96 \pm 0.24(n=3)$ & $1.12 \pm 0.27(n=3)$ \\
\hline
\end{tabular}

Summary of blue-ON cell chromatic response properties for four experimental conditions including controls and the effects of GABAa/c and glycine receptor antagonists (rows). From left to right, the first column summarizes the balance of S:LM amplitudes in response to $16 \%$ contrast, $2 \mathrm{~Hz}$ pulses; second column, response linearity of $\mathrm{S}$ and LM inputs calculated as (LM-S) responses versus the sum of individual $\mathrm{S}$ and $\mathrm{LM}$ responses to $16 \%$ contrast, $2 \mathrm{~Hz}$ pulses; third column, relative balance of S:LM cone input weights from sinusoidal fits to responses described in Figure 3; fourth column, S:LM radii (in micrometers) estimated from Gaussian fits to the spatial modulation transfer functions; and fifth column, estimated S:LM integrated volumes from the Gaussian fits to the spatial modulation transfer functions.

ment. For a cell with balanced inputs the $\mathrm{S}$ $\mathrm{ON}$ and LM OFF responses should be equal and for a linear cell the LM-S response should equal the sum of individual $S$ ON and LM OFF responses, whereas an LMS stimulus would elicit no net modulation. For a typical response, shown in Figure $2 \mathrm{H}$, the calculated fundamental Fourier (F1) response amplitude to modulation of the $S$ cone $=20$ spikes $/ \mathrm{s}$, LM cones $=21$ spikes $/ \mathrm{s},(\mathrm{LM}-\mathrm{S})$-cones $=$ $41 \mathrm{spikes} / \mathrm{s}$, and no significant response to in-phase modulation of all three cones (LMS). This result was consistent across cells and showed that at low contrasts blue-ON cells receive relatively equally weighted $(\mathrm{S}: \mathrm{LM}=1.16 \pm 0.24$, mean \pm $\mathrm{SD}$, median $=1.13 ; n=67)($ Table 1$)$ and linear $(\mathrm{LM}-\mathrm{S}: \mathrm{S}+\mathrm{LM}=0.86 \pm 0.14$, mean $\pm \mathrm{SD}$, median $=0.87 ; n=67)(\mathrm{Ta}-$ ble 1) $\mathrm{S}$ and LM inputs.

A second stimulus protocol was designed to quantify the relative S versus LM cone input weights more systematically. Complete datasets were achieved in a subset of 51 cells in the total sample of 89 in which cone weights were estimated. The stimulus varied S and LM cone contrast and phase stepwise from equal cone contrasts in phase to equal contrasts in antiphase (Fig. $4 A$ ). The data were fit by a simple linear model of cone summation (Diller et al., 2004) and is described in detail in the Materials and Methods (see also Fig. 4, legend). As expected, blue-ON cells peak response typically occurred when the $\mathrm{S}$ and LM cones were modulated at equal depth (equal cone contrasts) and in antiphase and the response minimum was reached when the cones were modulated at equal depth and in phase (Fig. 4B). Assuming linear summation, the fit quantifies the S:LM weight. Thus, for the cell illustrated in Figure $4 B$ the calculated S:LM cone input weight equaled 0.97. S and LM normalized and averaged response amplitudes and phases were averaged to give an input weight ratio $(\mathrm{S}: \mathrm{LM})$ of $1.09 \pm 0.21$ (mean $\pm \mathrm{SD}$; median $=$ $1.56 ; n=51$ ) (Fig. $4 C$, Table 1 ).

\section{$S$ and LM cone contrast and temporal sensitivity}

The relative balance of $S$ and LM inputs was also tested at a range of lower and higher contrasts and temporal frequencies. Contrast
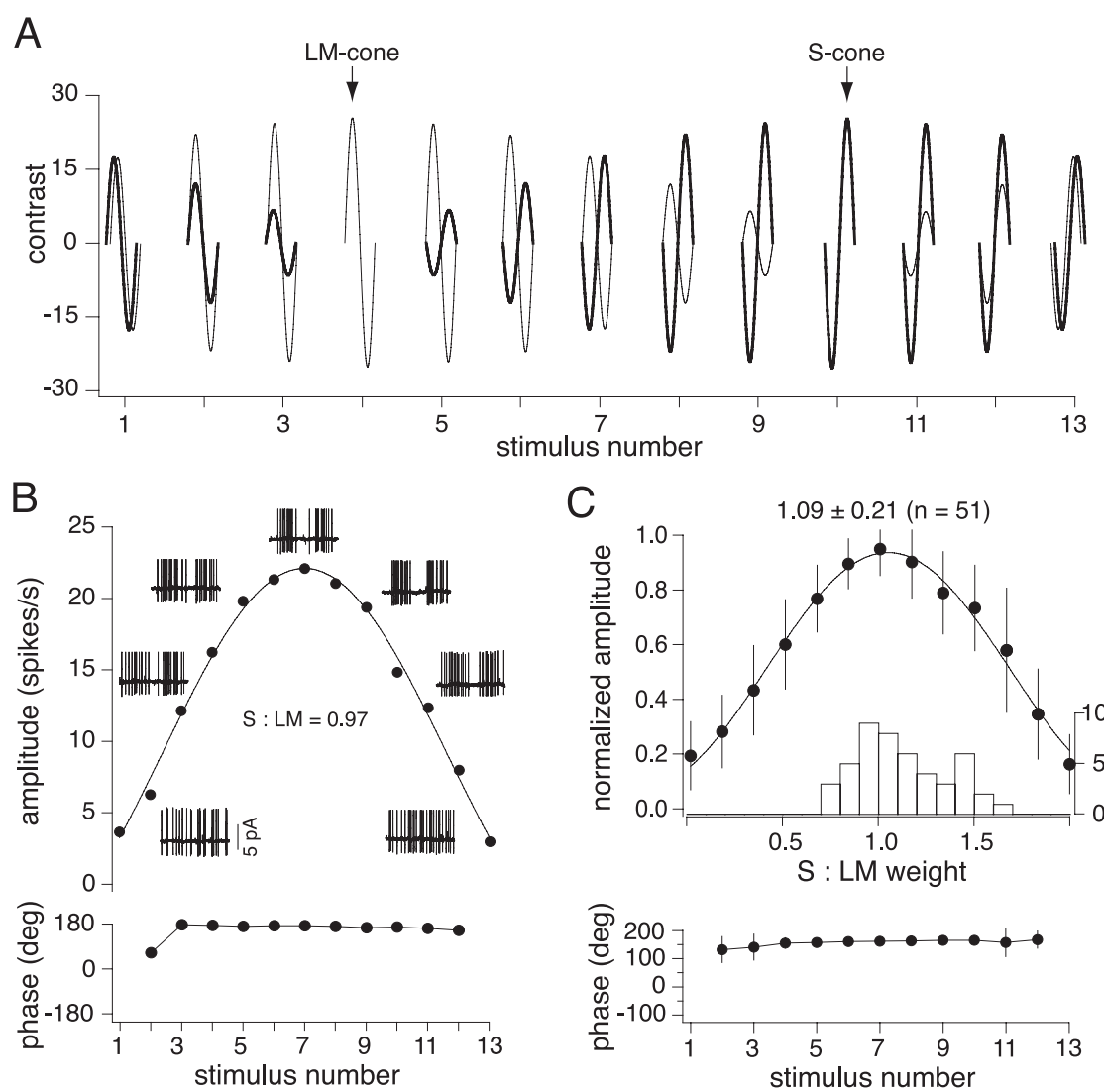

Figure 4. Relative $S$ and LM input weights are equal based on linear fit estimates to data collected in response to systematic variations in the contrast and phase of $S$ and $L M$ cone-isolating stimuli. $A$, The contrast and phase of LM (thin lines) and $S$ cone (thick lines)-isolating stimuli was varied systematically in 13 graded steps at $2 \mathrm{~Hz}$, beginning and ending with equal contrast, and passing through a midpoint (stimulus number 7 ) of equal and opposite contrast. $\boldsymbol{B}$, Response amplitude (top) and phase (below) for a blue-ON cell to the stimuli described in $A$. Data were fit with a linear model (solid line), and the peak response relative to the stimulus contrast provides a quantitative estimate of the relative $S$ and $L M$ cone input weights. A purely opponent cell has a peak response to opposite and equal LM and S cone-isolating stimuli (stimulus number 7), such that $S: L M=1$. For a cell that receives more LM input, $S: L M<1$; for more S input, S:LM $>1$. The calculated S:LM input weight for the cell shown was 0.97 , and the response phase was invariant for all but the smallest responses. Insets show the odd-numbered conditions. $C$, Summary of response amplitudes (normalized), phases, and weights (inset histogram; mean $\pm S D=1.11 \pm 0.23 ; n=52$ ) to the protocol described above. Error bars indicate SD.

sensitivity was compared using $\mathrm{S}$ and LM cone-isolating stimuli between 2 and 38\%, which were the maximal cone contrasts that we could achieve on a background of equal mean quantal catch for all three cone types. Both LM and $\mathrm{S}$ responses increased linearly with contrast (Fig. 5A). The slope of a straight line fit to the data was used to quantify contrast gain (Fig. $5 B$ ). The average contrast gain for the $\mathrm{S}$ was $1.26 \pm 0.49($ mean $\pm \mathrm{SD} ; n=8)$ and for the LM input $1.25 \pm 0.25$ (mean $\pm \mathrm{SD} ; n=8$ ). These overlap with contrast gain values calculated from extracellular recordings of $L$ versus $M$ and $S$ versus LM opponent cells in the intact animal (Yeh et al., 1995; Solomon et al., 2005; Tailby et al., 2008) and 

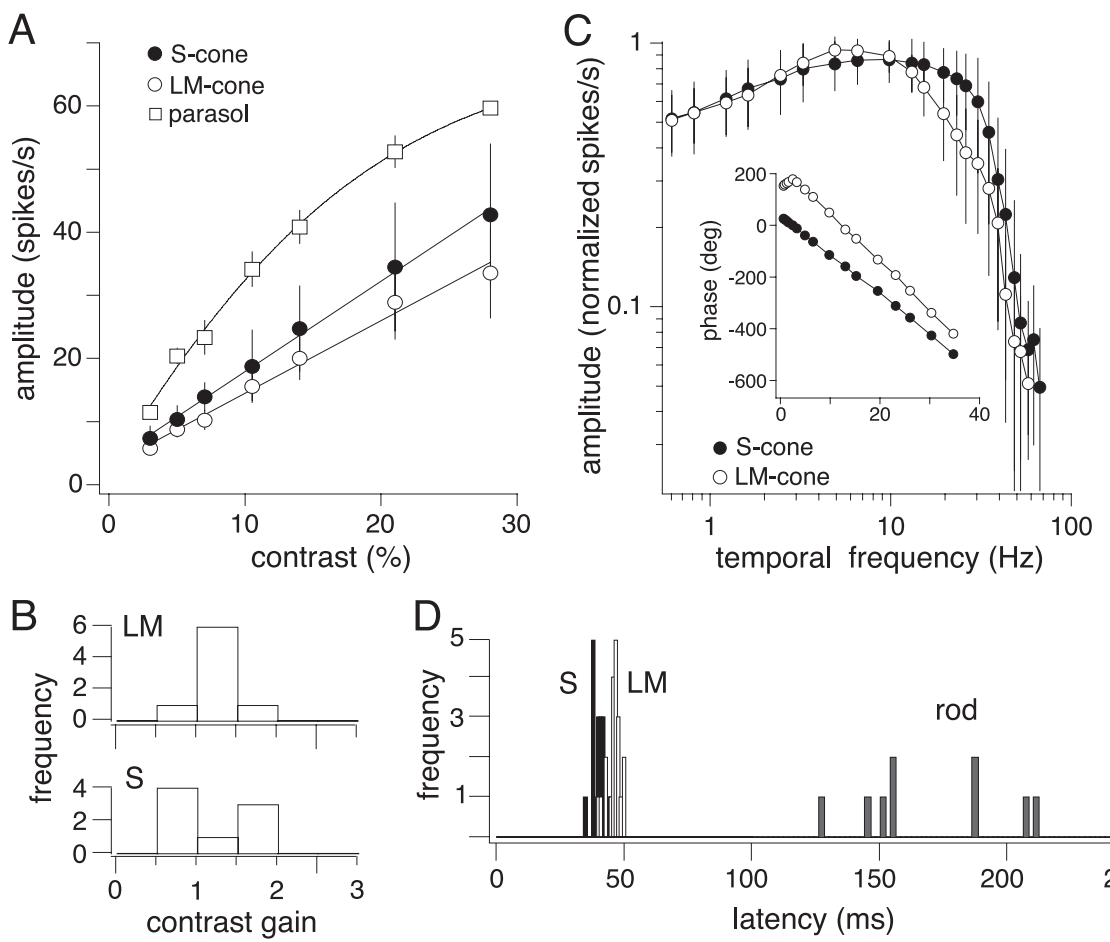

Figure 5. Blue- $0 \mathrm{~N}$ cells $S$ and $L M$ receptive fields have similar contrast and temporal sensitivities. $A$, Average contrast response functions measured with low spatial frequency $(0.047 \mathrm{cpd})$ gratings with $S$ (solid circles, $n=4)$ and LM (open circles, $n=4$ ) cone-isolating stimuli ( $4 \mathrm{~Hz}$ ), and an average contrast response function for parasol cells (open squares, $n=3$ ) measured with the same $\mathrm{LM}$ cone-isolating stimuli used for blue- $0 \mathrm{~N}$ cells presented at an optimal spatial and temporal $(10 \mathrm{~Hz})$ frequency. Blue- $0 \mathrm{~N}$ cells have a linear contrast response function, fit with a line, whereas parasol cells show high-contrast sensitivity and responses were best fit with a Naka-Rushton saturation function (see Materials and Methods). Error bars indicate SD. B, Summary of blue- $0 \mathrm{~N}$ cells $S$ and $L M$ contrast gain values reflecting the slope of linear fits (solid lines in $\boldsymbol{A}$ ) to all the amplitude data. $\boldsymbol{C}$, The average normalized (response/peak response) temporal modulation transfer functions for $S$ (solid circles, $n=20$ ) and LM cone (open circles, $n=20$ )-isolating stimuli presented in a $2000 \mu \mathrm{m}$ spot at $48 \%$ contrast. Inset shows the $S$ and LM phase data for one cell. The phases of the $S$ and LM inputs are initially $\sim 180$ degrees offset and converge with increasing temporal frequency. The linear portion of the phase data was fit with a straight line to calculate the latency. $D$, Summary of rod, $S$, and LM response latencies calculated from the slope of linear fits to the phase (Figs. 3B, 5 C, inset). The average rod latency $=177 \pm 36 \mathrm{~ms}$ (mean \pm SD; $n=$ 10), Slatency $=40 \pm 3 \mathrm{~ms}$, and LM latency $=46 \pm 3 \mathrm{~ms}($ mean $\pm S D ; n=20)$.

were somewhat lower than that for the well studied magnocellular-projecting ganglion cells in response to an achromatic stimulus (Crook et al., 2008). To illustrate this distinct difference, we recorded from neighboring magnocellular projecting parasol cells using the same LM stimulus (parasol cells did not respond to $\mathrm{S}$ cone-isolating stimuli) at an optimal spatial and temporal frequency $(10.5 \mathrm{~Hz})$. Parasol cells show extreme sensitivity to low contrasts with response amplitudes more than doubling to two-fold increases in contrast (Fig. $5 \mathrm{~A}$, squares). The parasol cell contrast response functions were well fit with NakaRushton saturation functions (see Materials and Methods) and contrast gain values were calculated from the initial linear portion of the curve. On average the contrast gain was $4.85 \pm 0.37$ (mean $\pm \mathrm{SD} ; n=3$ ).

We compared LM and S temporal sensitivities with coneisolating stimuli ( $2 \mathrm{~mm}$ diameter field) sinusoidally modulated at $25-48 \%$ contrast at temporal frequencies ranging from $0.61-78$ Hz. S-ON and LM-OFF inputs were both sensitive to temporal frequencies up to $60 \mathrm{~Hz}$ with similar peak responses ( $\mathrm{S}$ cone $=$ $11 \pm 7 \mathrm{~Hz}$ and $\mathrm{LM}$ cone $=7 \pm 2 \mathrm{~Hz}$, mean $\pm \mathrm{SD} ; n=20$ ) (Fig. $5 C$ ). The inset in Figure $5 C$ plots the corresponding phase data for one cell. The phases of the S and LM inputs were initially $\sim 180$ degrees offset and converged with increasing temporal frequency. For each cell, the linear portion of the phase data was fit with a straight line to calculate the latency. For the cell shown in the inset to Figure $5 C$, the $\mathrm{S}$ input latency was $42 \mathrm{~ms}$ and the LM 48 ms. Across cells, the response to $\mathrm{S}$ cone stimuli showed slightly shorter latencies than that for LM stimuli ( $\mathrm{S}$ mean latency $\pm \mathrm{SD}=40 \pm 3 \mathrm{~ms}$; LM mean latency $\pm \mathrm{SD}=46 \pm 3 \mathrm{~ms} ; n=20$ ) (Fig. $5 D)$. Our data are approximately consistent with those reported from measurements using comparable stimuli made in the intact eye in vivo (Yeh et al., 1995). In the study by Yeh et al. (1995), latencies of $\sim 35 \mathrm{~ms}$ were found for both the S and LM cone driven responses at comparable light levels to those used here. The reason for this discrepancy is unclear, although it could reflect effects of the in vitro maintenance on the temporal sensitivity of the retina. We have observed anecdotally a profound effect of retinal temperature on the response dynamics; while we attempt to keep our in vitro retinas as close to physiological temperature as possible (typically $\sim 35-36^{\circ} \mathrm{C}$ ), it is only possible to monitor temperature and a location in the superfusion chamber relatively distant from the recording site, so precise temperatures and temperature fluctuations are not known. In another recent study recording from blue-ON cells in the in vitro retina, much longer latencies of $\sim 50$ and $70 \mathrm{~ms}$ for the $S$ and LM cone inputs, respectively, were reported (Field et al., 2007). However, retinal illuminance was lower in this study and latencies were calculated from time to peak of the spike-triggered average derived from a white noise stimulus, so it is possible that these methodological differences also contributed to the additional deviation from that found in vivo. Overall, our data are consistent with previous work from recordings in the intact animal suggesting similar temporal and contrast sensitivities for S ON and LM OFF inputs to the blue-ON ganglion cell.

\section{Coextensive $S$ and LM cone receptive fields}

To test whether blue-ON cells had center-surround or coextensive receptive field structure, the $\mathrm{S}$-ON and LM-OFF receptive fields of 55 blue-ON cells were mapped with either drifting sinusoidally modulated gratings that varied in spatial frequency, or sinusoidally modulated spots and annuli as a function of increasing diameter. Regardless of stimulus, both receptive fields showed similar or identical spatial tuning (Fig. $6)$. For drifting grating stimuli, both the $S$ and LM spatial frequency responses were low pass (Fig. $6 A, D$ ) with comparable peak responses at the lowest spatial frequencies tested and similar high spatial frequency cutoffs. To a spot centered on the cell's receptive field (Fig. $6 \mathrm{~B}$ ), LM and S response magnitudes peaked when spot diameter approximated the expected diameter of the dendritic tree of a small bistratified cell (Dacey, 1993). The response plateaued at this diameter (usually between 75 and $200 \mu \mathrm{m}$ ) (Fig. $6 B$ ), suggesting little or no surround antagonism. If a surround was present, increasing 

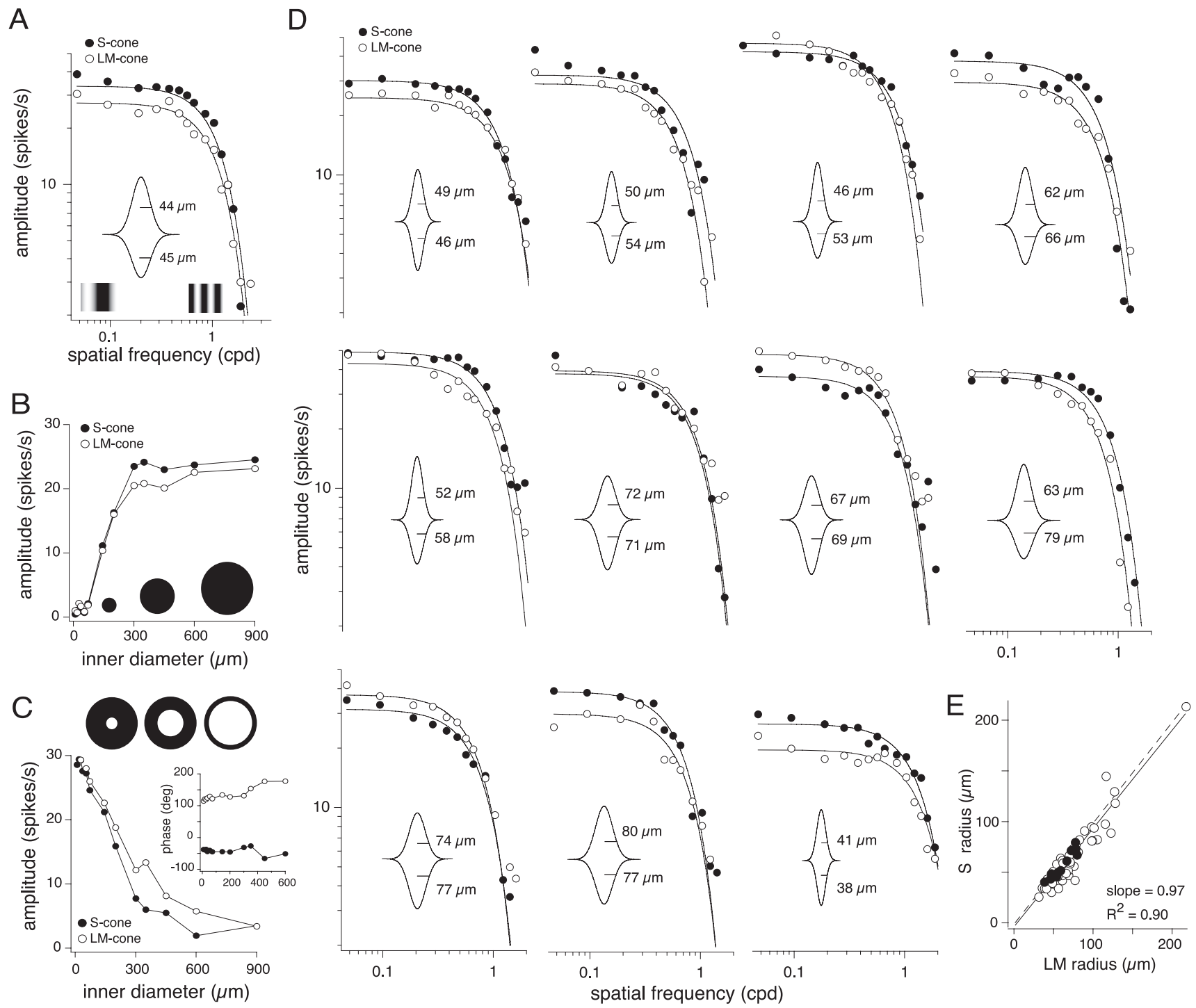

Figure 6. Blue-ON S and LM receptive fields are low pass and nearly coextensive. Receptive fields were mapped with LM and S cone-isolating drifting gratings as a function of spatial frequency, or spots and annuli as a function of center diameter. All spatial stimuli were presented at $4 \mathrm{~Hz}$ and at $22-36 \%$ contrast on a background in which the mean photoisomerizations were equal for all three cone types. $A, S$ (solid circles) and LM (open circles) receptive fields mapped with drifting gratings; solid lines are Gaussian fits to the data, and a model $2 D$ receptive field profile is shown in the inset with the calculated Gaussian radii of $44 \mu \mathrm{m}$ for S and $45 \mu \mathrm{m}$ for LM. B, Responses to S and LM cone-isolating spot stimuli of increasing diameter as indicated by the schematic [1 degree of visual angle corresponds to $\sim 200 \mu \mathrm{m}$ on the retinal surface (Schein, 1988)]. C, Responses to $S$ and LM cone-isolating annuli stimuli of increasing inner diameter as indicated by diagram representations. The inset plots the corresponding phase data showing $S$ (solid circles) and LM (open circles) phases $\sim 180$ degrees apart. Responses in $\boldsymbol{A}-\boldsymbol{C}$ are from the same cell. $\boldsymbol{D}$, Receptive fields mapped for 11 blue- $0 \mathrm{~N}$ cells with drifting gratings as described in $A$. $E$, Estimated LM versus $S$ receptive field Gaussian radii (in micrometers) for 55 blue- $0 \mathrm{~N}$ cells (open circles; mean $\pm S D=1.12 \pm 0.19$ ). Solid circles represent the cells presented in $\boldsymbol{A}$ and $\boldsymbol{D}$. The dashed line shows the unity slope and the solid line the actual fit to the data, which had a slope of $0.97\left(R^{2}=0.90\right)$.

spot size to encroach on the surround should attenuate the response. To an annulus centered on the cell's receptive field (Fig. 6C), the maximum response for both the LM and S inputs occurred when the inner diameter was smallest $(9 \mu \mathrm{m})$. As the annulus center increased, both ON and OFF inputs rolled off with no sign of a reversal in the response phase (Fig. $6 C$, inset) as would be indicative of a surround. Low-pass $S$ and LM spatial frequency responses were thus well fit with a single Gaussian. Examples in Figure 6, $A$ and $D$, show the Gaussian fits (solid lines) and the inset in each plot shows the model two-dimensional (2D) receptive field profile and calculated Gaussian radii $(\mu \mathrm{m}) . S$ and LM cone driven receptive field sizes were nearly identical ( $S$ to LM diameter ratio from the
Gaussian fits $=0.92 \pm 0.13$, mean $\pm \mathrm{SD}$; median $=0.94 ; n=$ 55) (Table 1) and the slope of the fit to LM versus $S$ Gaussian radii in Figure $6 E$ was equal to $0.97\left(R^{2}=0.90\right)$. The peak response amplitudes ( $\sim 30$ spikes/s) were also typically matched for the $\mathrm{S}$ and $\mathrm{LM}$ responses $(\mathrm{S}: \mathrm{LM}$ response ratio $=$ $1.19 \pm 0.38$, mean $\pm S D$; median $=1.19 ; n=55)$. Thus, the $S$ and LM fields are well matched in both size and sensitivity.

To summarize, the S-ON and LM-OFF inputs show similar contrast and temporal sensitivities; the two fields are also nearly equal in area and sensitivity, consistent with a spatially coextensive pattern (Fig. 1A). To explore the retinal circuitry that generates the S-ON and LM-OFF responses (Fig. 1C), we used pharmacological manipulation to assess the role of exci- 
A

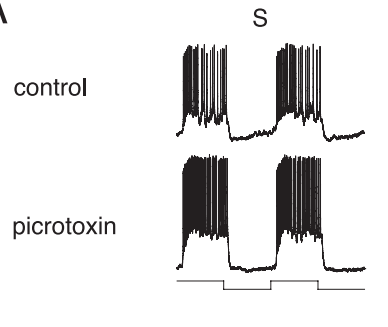

S LM

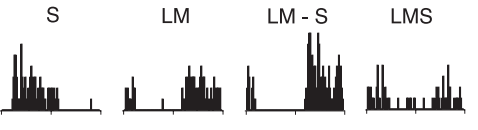

S LM

picrotoxin

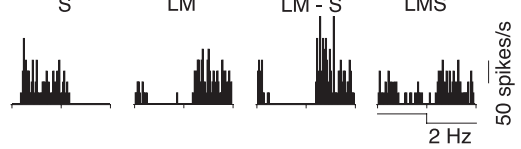

B

control

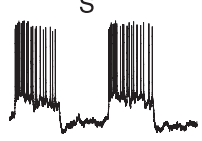

strychnine
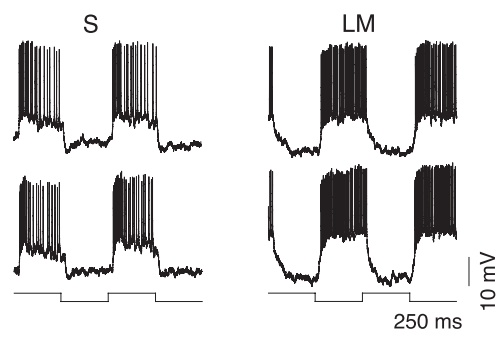

control LM

strychnine

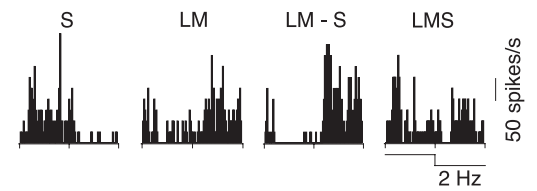

C

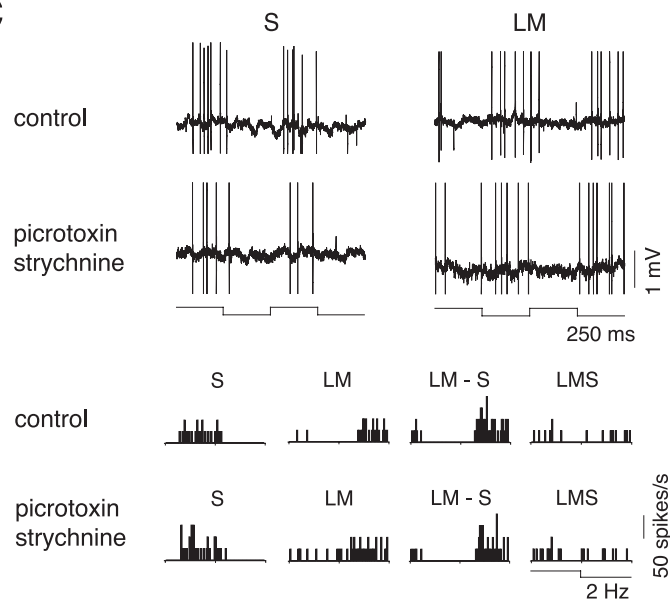

D
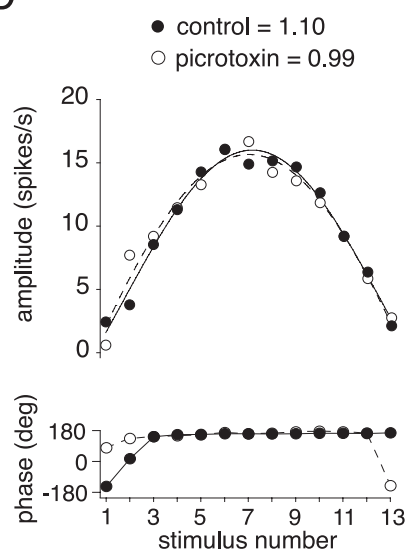

E
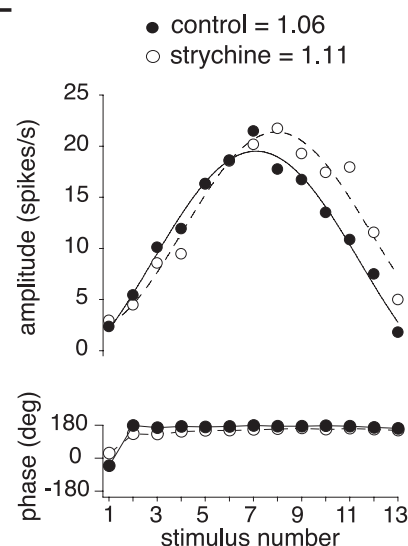

F
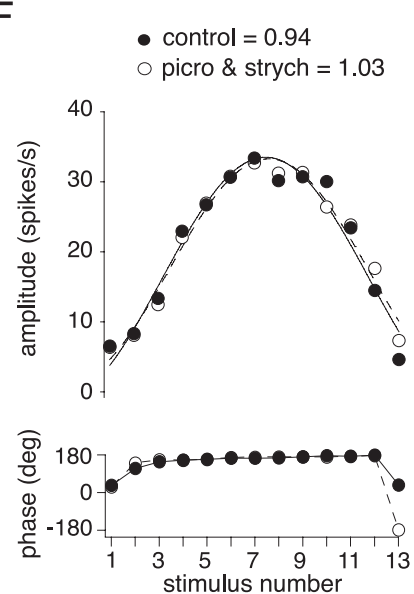

G control picrotoxin

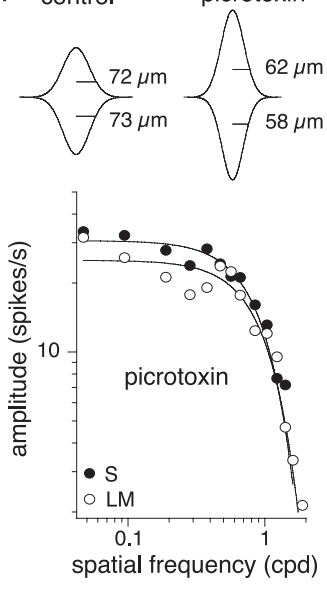

H control strychnine

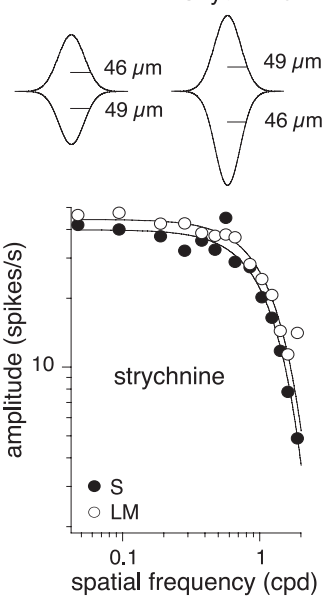

I

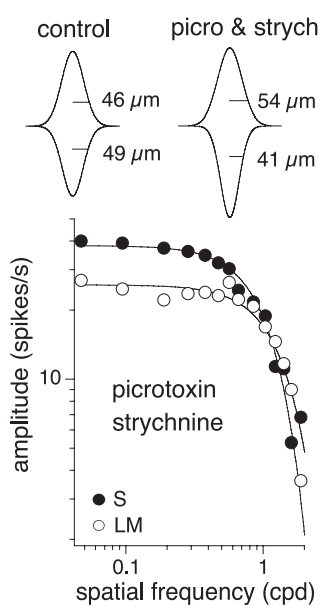

Figure 7. Blue-ON cells balanced and coextensive $S$ and $L M$ inputs were not dependent on inhibitory amacrine cells. $A-C$, Voltage responses and spike histograms to cone-isolating pulses as described in Figure 2 recorded before (top in $\boldsymbol{A}, \boldsymbol{B}$, and $\boldsymbol{C}$ ) and after the addition of GABAa/c and/or glycine receptor antagonists: picrotoxin ( $\boldsymbol{A}$, bottom), strychnine (B, bottom), and picrotoxin and strychnine together ( $\boldsymbol{C}$, bottom). $\mathbf{D}-\boldsymbol{F}$, The relative weight of S:LM inputs were quantified using the protocol described in Figure 4 . Response amplitudes, phases, and fits are plotted for control conditions (solid circles) and in the presence of picrotoxin $(\boldsymbol{D})$, strychnine $(\boldsymbol{E})$, and picrotoxin and strychnine together $(\boldsymbol{F})$ (open circles). The calculated S:LM input weights from the fits for control and drug conditions are shown above the plots. $\mathbf{G}-\mathbf{I}, \mathrm{LM}$ and $\mathrm{S}$ receptive fields were mapped with drifting gratings ( $28-36 \%$ contrast, $4 \mathrm{~Hz}$ ) and fit with Gaussian models before and after the addition of GABAa/c and/or glycine receptor antagonists. Plots show the receptive fields mapped in the presence of picrotoxin $(\boldsymbol{G})$, strychnine $(\boldsymbol{H})$, and picrotoxin and strychnine together $(\boldsymbol{I})$ and include the Gaussian model fits (solid lines) calculated from the spatial modulation transfer functions for control conditions and in the presence of the indicated drug. The 2D receptive field profiles above the plots include the estimated S and LM Gaussian radii. 
tatory $\mathrm{ON}$ pathway and inner retinal inhibitory pathway input to the small bistratified cell.

Opponent responses are not generated by inner retinal inhibitory pathways

A large percentage of inputs to the small bistratified cell are from amacrine cells (Calkins et al., 1998; Ghosh and Grünert, 1999). We therefore assessed whether inhibitory amacrine input had a major role in generating the balance of S versus LM inputs or shaping their coextensive receptive fields. We recorded responses from blue-ON cells in the presence of picrotoxin, a general GABAa/c receptor antagonist, and strychnine, a glycine receptor antagonist, both in combination and alone, using the same stimuli used to measure S versus LM input strength (Fig. 4) and receptive field spatial structure (Fig. 6). Qualitatively, the intracellular and spike histogram responses to coneisolating stimuli presented in Figure $7 A-C$ clearly illustrate that the blue-ON cell's $S$ and LM opponency was not greatly enhanced or attenuated in the presence of picrotoxin (Fig. $7 A$ ), strychnine (Fig. $7 B$ ), or picrotoxin and strychnine together (Fig. 7C). Furthermore, the $S$ and $\mathrm{LM}$ response amplitudes and $\mathrm{LM}-\mathrm{S}$ versus LMS ratios calculated from the histograms were indistinguishable from the controls for all three conditions (Table 1). The sensitivity and balance of the $S$ and $L M$ cone input weights to incremental changes in contrast, measured with the protocol described in Figure 4, was also maintained. For picrotoxin and strychnine alone (Fig. $7 D, E$, open circles), and picrotoxin and strychnine together (Fig. 7F, open circles), the responses, fits, and relative $S$ versus LM cone input weights (Table 1) overlapped the controls (Fig. 7D-F, solid circles). Blocking the inhibitory pathways also had no effect on the relative sensitivity or spatial extent of the $S$ and LM receptive fields. Using cone-isolating drifting gratings, the $S$ and LM receptive fields were measured in the presence of picrotoxin (Fig. $7 G$ ), strychnine (Fig. $7 \mathrm{H}$ ), and picrotoxin and strychnine together (Fig. 7I). For each condition, the S and LM spatial frequency responses remained low pass, coextensive, and well fit with a Gaussian receptive field model (solid lines). These results are summarized in Table 1, showing the S:LM radii and integrated volumes ratios. For all three conditions, there was no change compared with the controls. Overall, blue-ON cells remained opponent (Fig. 7A-C) with equally weighted $S$ and LM inputs (Fig. $7 D-F$ ) and with intact, approximately coextensive, low-pass LM and $S$ receptive fields (Fig. 7G-I). However, for the intracellular recordings to high

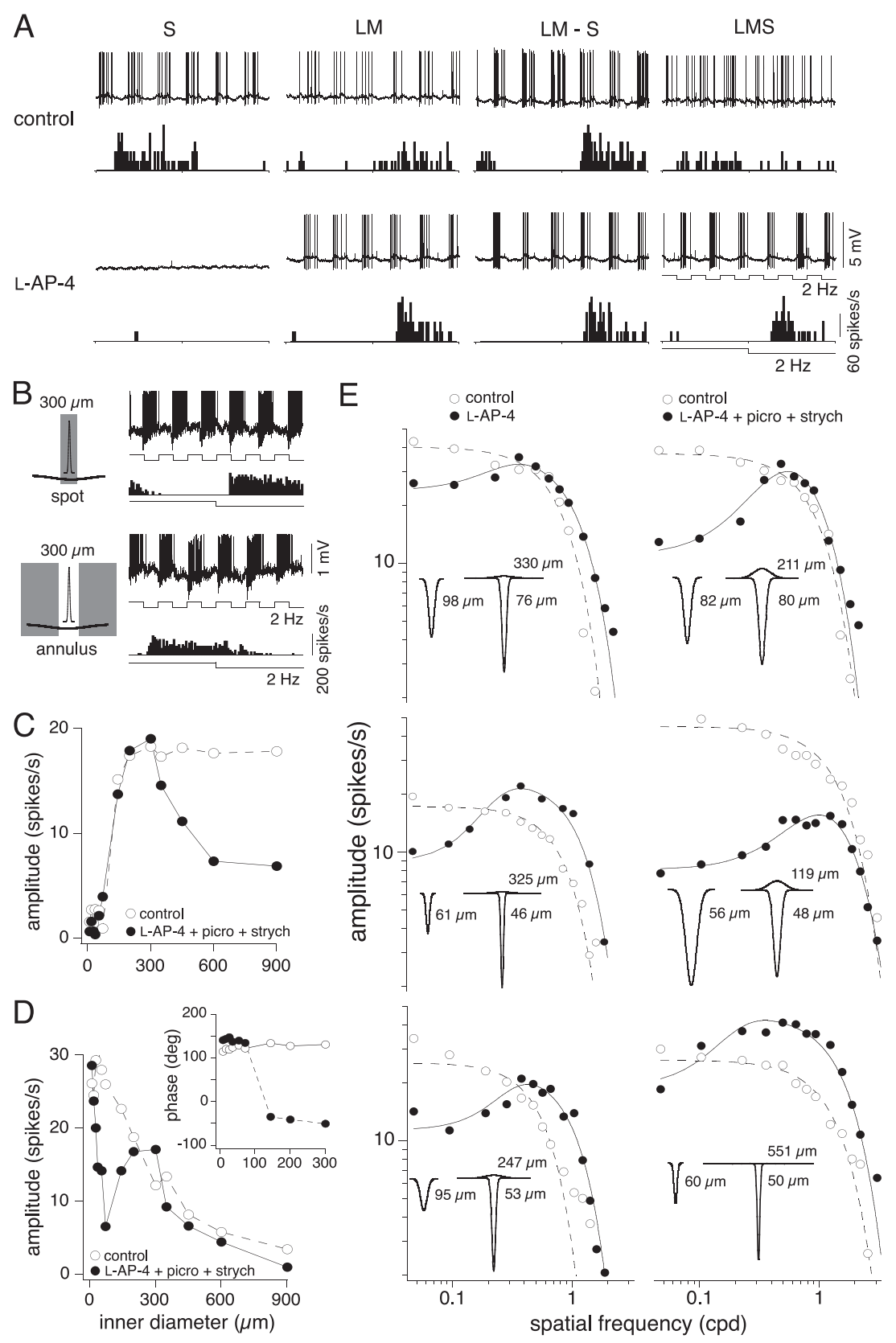

Figure 8. The receptive field of the LM OFF input isolated with L-AP-4 shows center-surround organization. $\boldsymbol{A}$, Voltage responses and spike histograms to full field cone-isolating pulses as described in Figure 2 ( $2 \mathrm{~Hz}, 16 \%$ contrast) before (above) and after (below) the addition of L-AP-4. With no SON input, responses to LM-S and LMS stimuli are the same as responses to $L M$ stimuli. $\boldsymbol{B}$, In the presence of L-AP-4, the isolated LM input responds to the offset of a $300 \mu \mathrm{m}$ spot and to the onset of an annulus with a $300 \mu \mathrm{m}$ inner diameter, as indicated by the phase of the responses traces and spike histograms. $\boldsymbol{C}$, Responses to LM cone-isolating spot stimuli ( $28 \%$ contrast, $4 \mathrm{~Hz}$ ) of increasing diameter before (open circles) and after the addition of L-AP-4, picrotoxin, and strychnine (solid circles). D, Responses to LM cone-isolating annuli stimuli ( $28 \%$ contrast, $4 \mathrm{~Hz}$ ) of increasing inner diameter recorded before (open circles) and after the addition of L-AP-4, picrotoxin, and strychnine (solid circles). The inset plots the corresponding phase data that shifts $\sim 180$ degrees once the diameter of the annulus reaches $\sim 100 \mu \mathrm{m}$, indicating an ON-surround. $\boldsymbol{E}$, Plots showing LM receptive fields mapped for six cells with drifting gratings $(28-100 \%, 4 \mathrm{~Hz}$ ) before (open circles) and after (solid circles) the addition of L-AP-4 alone (left) or L-AP-4, picrotoxin, and strychnine (right). Before silencing the S-ON pathway the LM receptive field was low pass and fit with a Gaussian model, whereas in the presence of L-AP-4 the isolated LM receptive field was bandpass and fit with a difference-of-Gaussians model. Insets show 2D receptive field profiles for both conditions with the estimated LM center and surround Gaussian radii (in micrometers) indicated. 
A

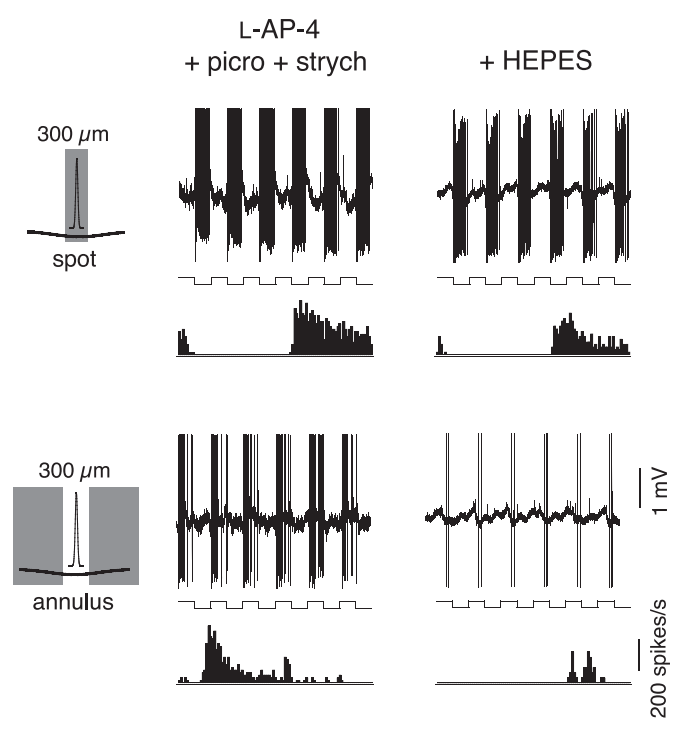

B
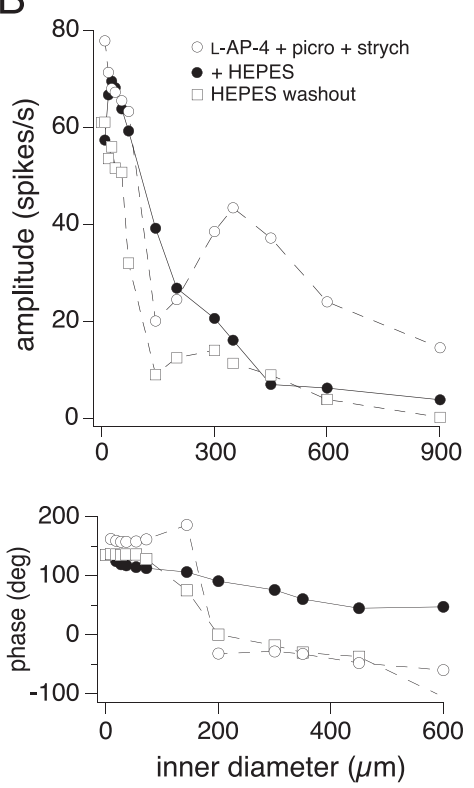

C

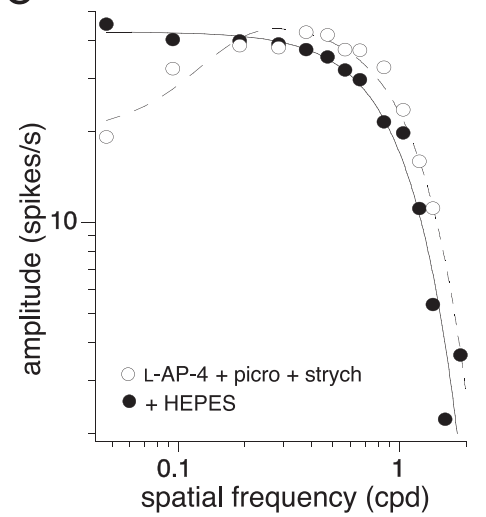

D

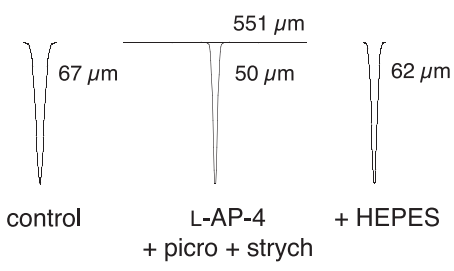

Figure 9. In the presence of $\mathrm{L}-\mathrm{AP}-4$, the isolated LM surround was sensitive to HEPES. A, In the presence of $\mathrm{L}-\mathrm{AP}-4$, picrotoxin, and strychnine, the isolated LM input responds to the offset of a 300 $\mu \mathrm{m}$ spot and to the onset of an annulus with a $300 \mu \mathrm{m}$ inner diameter as indicated by the phase of the voltage responses (top) and spike histograms (bottom). The addition of HEPES to L-AP-4, picrotoxin, and strychnine abolishes the LM ON surround, and the cell responds to the offset of both a spot and annulus. B, Response amplitude (top) and phase (bottom) to annuli stimuli (100\% contrast, $4 \mathrm{~Hz}$ ) of increasing inner diameter measured in the presence of L-AP-4, strychnine, and picrotoxin (open circles); $\mathrm{L}-\mathrm{AP}-4$, strychnine, picrotoxin, and HEPES (solid circles); and after wash out of HEPES with L-AP-4, strychnine, and picrotoxin still present (open squares). The isolated LM ON surround response is indicated by the shift in the response phase when the inner diameter reaches at least $150 \mu \mathrm{m}$. C, Plot showing the isolated LM receptive field mapped with drifting gratings ( $4 \mathrm{~Hz}, 28 \%$ and $100 \%$ contrast) in the presence of L-AP-4, strychnine, and picrotoxin (open circles), and L-AP-4, strychnine, picrotoxin, and HEPES (solid circles). The bandpass receptive field measured in the presence of L-AP-4 was fit with a difference-of-Gaussians model (solid line) and became low pass with the addition of HEPES (fit with a Gaussian receptive field model, solid line). $\boldsymbol{D}$, The LM $2 \mathrm{D}$ receptive field profiles and Gaussian radii (in micrometers) derived from the spatial frequency responses in $C ; S$ and LM Gaussian radii (in micrometers) are indicated. Fits were also made to responses recorded under the same three conditions for two other cells. For the cell with voltage responses shown in $\boldsymbol{A}$ (original LM center radius $=82 \mu \mathrm{m}$ ), in the presence of L-AP-4, strychnine, and picrotoxin, center and surround radii $=62$ and $237 \mu \mathrm{m}$, respectively. With the addition of HEPES, center radius $=81 \mu \mathrm{m}$ with no measurable surround. For the third cell (data not shown; original LM center radius $=56 \mu \mathrm{m}$ ), in the presence of $\mathrm{L}-\mathrm{AP}-4$, strychnine, and picrotoxin, center and surround radii $=48$ and $118 \mu \mathrm{m}$, respectively. With the addition of HEPES, center radius $=79 \mu \mathrm{m}$ with no measurable surround.

sponse at the stimulus frequency (Fig. 7A) (picrotoxin/control $\mathrm{S}=1.63 \pm 0.14$ and $\mathrm{LM}=1.44 \pm 0.22$, mean $\pm \mathrm{SD} ; n=3)$. The LM responses also hyperpolarized more slowly at the onset of the light stimulus (Fig. 7A). The width of the LM response, measured at $1 / 3$ the maximum response amplitude, increased from $264 \pm$ $10 \mathrm{~ms}$ to $316 \pm 13 \mathrm{~ms}$ (mean $\pm \mathrm{SD} ; n=3$ ), while the width of the $S$ response was unchanged, from $246 \pm 4 \mathrm{~ms}$ to $245 \pm 8 \mathrm{~ms}$ (mean $\pm \mathrm{SD} ; n=3$ ). In the presence of strychnine, the light responses were not significantly changed in amplitude (Fig. $7 B$ ) (strychnine/control $\mathrm{S}=0.92 \pm 0.12$ and $\mathrm{LM}=1.04 \pm 0.07$, mean $\pm \mathrm{SD} ; n=3$ ) or width (S control $=241 \pm 6 \mathrm{~ms}$ and S strychnine $=243 \pm 8 \mathrm{~ms} ; \mathrm{LM}$ control $=257 \pm 14 \mathrm{~ms}$ and LM strychnine $=252 \pm 19 \mathrm{~ms}$, mean $\pm \mathrm{SD} ; n=3$ ). We conclude that inner retinal inhibitory pathways may play a role in shaping the amplitude and dynamics of the $S$ and LM response, but that these pathways are not essential for generating the LM-OFF component of the blue-ON cell response.

\section{ON pathway block isolates an LM OFF field with center-surround organization}

To directly test the hypothesis that input from the ON pathway generates the small bistratified cell's S-ON response and that the LM-OFF response arises from a parallel OFF bipolar pathway synaptic input (Calkins et al., 1998; Ghosh and Grünert, 1999), we recorded responses to cone-isolating stimuli in the presence of the mGluR6 receptor agonist L-AP-4 to block ON pathway transmission (Slaughter and Miller, 1981). The L-AP-4 was also applied in combination with strychnine and picrotoxin to isolate excitatory OFF pathway input to the small bistratified cell. The addition of L-AP-4 abolished the S-ON response while sparing the LM-OFF response. Robust LM-OFF responses of similar amplitude were recorded to LM, LM-S and LMS cone modulation (Fig. $8 \mathrm{~A}$ ). With S-ON input blocked the LM-S and LMS stimuli now elicited responses equivalent to pure LM stimuli. In 22 out of 22 blue-ON cells, we recorded only LM-OFF responses in the presence of L-AP-4 or L-AP-4, picrotoxin, and strychnine.

After elimination of the S-ON response by L-AP-4, we mapped the spatial receptive field of the isolated LM-OFF input for 13 cells and found responses at low spatial frequencies were strongly attenuated, indicating the presence of surround antagonism not observed when the S-ON component was present in the control situation. The presence of a surround in the isolated LM response was confirmed using spot and annular stimuli. Thus, a $300 \mu \mathrm{m}$ diameter spot elicited the expected LM-OFF response, but a $300 \mu \mathrm{m}$ inner diameter annulus elicited an LM-ON response (Fig. $8 B$ ). The surround was clearly observed by centering a spot on the cell's receptive field and increasing its inner diameter. Initially, like the control, responses increased and peaked as the size of the spot covered the center, but with increasing spot size the response amplitude decreased as the spot grew and stimulated the antagonistic surround (Fig. 8C). Similarly, the control LM OFF response to an annulus of increasing inner diameter peaks and then declines (Fig. $8 D$, open circles) with no change in response phase (Fig. $8 D$, inset, open circles). In contrast, in the presence of L-AP-4, picrotoxin, and strychnine the LM-OFF response initially peaks but then declines until the annulus inner 
diameter reaches $\sim 150 \mu \mathrm{m}$ and isolates an $\mathrm{LM}-\mathrm{ON}$ surround response as indicated by an $\sim 180^{\circ}$ shift in the response phase. (Fig. $8 D$, inset, solid circles). The LM-ON response then peaks and declines as the inner diameter increases further (Fig. $8 D$, solid circles). Finally, in the presence of either L-AP-4 alone (Fig. $8 \mathrm{E}$, left column) or L-AP-4 and the GABAa/c and glycine receptor antagonists (Fig. $8 \mathrm{E}$, right column), low spatial frequency drifting gratings stimulated the broad antagonistic surround changing the spatial tuning from low pass to bandpass. L-AP-4 thus shifted the average peak response from a low spatial frequency (control: $0.047 \pm 0 \mathrm{cpd}$; mean $\pm \mathrm{SD} ; n=13)$ to a much higher spatial frequency $(0.461 \pm 0.217 \mathrm{cpd}$; mean $\pm \mathrm{SD} ; n=13)$. The resulting spatial frequency responses were best fit with a difference-of-Gaussian receptive field model rather than the single Gaussian model used for the controls (Fig. 8E). From the fits, the surround was estimated to be on average $\sim 4$ times larger than the center. By contrast, the center radius was unchanged under all conditions (control center radius/center radius after L-AP-4 alone $=1.35 \pm 0.16$, mean $\pm \mathrm{SD}, n=7$; after L-AP-4, picrotoxin, and strychnine = $1.34 \pm 0.42$, mean $\pm \mathrm{SD}, n=6$ ). The average sensitivity, measured as the amplitude of the peak response, was unchanged but more variable with the blockers present (control: $37 \pm 9$ spikes/s vs drug: $34 \pm 17$ spikes/s; mean \pm SD; $n=13$ ). Thus, responses in the presence of either L-AP-4 alone or L-AP-4, picrotoxin, and strychnine reveal that blue-ON cells receive $\mathrm{S}-\mathrm{ON}$ input via the ON pathway and are consistent with LM input from OFF cone bipolar cells that have center-surround organization. A hypothesis for the appearance of the surround in the LM OFF pathway when the ON pathway is blocked will be considered in Discussion.

\section{LM-ON surround may originate from a non-GABAergic feedback pathway}

The surround response was robust in the presence of either L-AP4 alone or L-AP-4 with strychnine and picrotoxin (Fig. $8 E$ ). The lack of effect of inner retinal inhibitory block on the centersurround structure of the isolated LM-OFF response suggested that a non-GABAergic and nonglycinergic pathway generated the surround. In previous studies, we showed that the cone-driven surrounds of parasol ganglion cells were also maintained after block of inner retinal inhibition (McMahon et al., 2004) but could be significantly attenuated by increasing the buffering capacity of the retina (Davenport et al., 2008), consistent with the interpretation that the surround was mediated by a novel nonGABAergic outer retinal feedback mechanism (Kamermans and Spekreijse, 1999; Hirasawa and Kaneko, 2003; Kamermans and Fahrenfort, 2004). We therefore used a similar protocol here, by adding HEPES buffer $(20 \mathrm{~mm})$ to the Ames medium to measure its effect on the center-surround organization for three of the cells in which the LM-OFF response had been isolated by L-AP-4, picrotoxin, and strychnine. The addition of HEPES attenuated the LM-ON response leaving only the center LM-OFF response intact (Fig. 9A,B), and with washout of HEPES the LM-ON responses were partially recovered (Fig. 9B). With HEPES buffering, the peak response to drifting gratings also now occurred at the lowest spatial frequency again $(0.047 \mathrm{cpd})$, like the original LM field, and the low-pass spatial frequency responses were fit with a Gaussian model (Fig. 9C). The results for the cell in Figure $9 C$ are summarized in the 2D Gaussian receptive field profiles (Fig. 9D) showing the LM receptive field before drug application (control, far left), the center and surround LM receptive field in the presence of L-AP-4, strychnine and picrotoxin (middle), and after the addition of HEPES (attenuating the LM-ON surround; right). Similar measurements for two other cells were also made and showed the same pattern (Fig. $9 D$, legend). Thus, much like that shown previously for the LM surround of parasol ganglion cells (Davenport et al., 2008) the "unmasked" ON-surround of the LM-OFF pathway input to the blue-ON cells may be mediated by non-GABAergic outer retinal feedback (Kamermans and Spekreijse, 1999; Kamermans and Fahrenfort, 2004; Cadetti and Thoreson, 2006).

\section{Discussion \\ Identification of Rod-ON input to small bistratified blue-ON cell}

After dark adaptation, rod input to the small bistratified cell is clearly present (Fig. 3). The sign of the rod signal follows that of the S-ON input: when rod input prevails, the blue-ON yellowOFF cell becomes a rod-ON cell. These results confirm an early observation of strong excitatory rod input to blue-ON cell relay cells recorded in the parvocellular LGN (Virsu et al., 1987), although a more recent study failed to observe a rod signal in blue-ON ganglion cells (Lee et al., 1997). In the primary rod pathway the depolarizing AII amacrine cell receives input from the rod bipolar cell and transmits the rod signal to ON cone bipolar cells via a sign-conserving gap junction and to OFF cone 
bipolar cells by a sign-inverting glycinergic synapse (Famiglietti and Kolb, 1975; Müller et al., 1988; Strettoi et al., 1992). The rod-ON response of the blue-ON ganglion cell could thus be mediated by an AII amacrine gap junction with the blue cone bipolar axon terminal; a preliminary report suggests such a contact is present (Marshak et al., 2009). In contrast, our data suggest a lack of the glycinergic synapse from the AII cell outer dendrites to the LM-OFF bipolar cell population(s) that are presynaptic to the small bistratified outer dendrites (Ghosh et al., 1997; Calkins et al., 1998). In this regard, there is growing evidence that certain mammalian bipolar cell types may not participate in the primary rod pathway (Völgyi et al., 2004; Petrides and Trexler, 2008). The degree to which rod signals might be restricted to distinct $O N$ and OFF cone bipolar pathways remains to be investigated in the primate. The rod-ON input to the blue-ON cell is consistent with a large body of human psychophysical data suggesting that rods interact synergistically with S-cones at mesopic levels to introduce a blue-bias to color appearance (for review, Buck, 2004). However, the current results do not exclude a rod-OFF input that is masked by a larger rod-ON signal or that arises at lower scotopic levels. Experiments that pharmacologically isolate potential $\mathrm{ON}$ and OFF components of the rod signal near threshold are needed to carefully address this question.

\section{Blue-ON cells show spatially coextensive receptive field structure}

Recording from the small bistratified cells in the choroidattached in vitro retina, we found that the S-ON and LM-OFF responses were spatially coextensive, or nearly so (Fig. 6), that the contrast gain and temporal response of the opponent fields were comparable (Fig. 5), and that at low to moderate cone contrasts LM and S cone inputs appear to sum linearly (Fig. 4). These results are broadly consistent with previous descriptions of the blue-ON cell at both the LGN (Wiesel and Hubel, 1966; Dreher et al., 1976; Derrington et al., 1984; Tailby et al., 2008) and retinal levels (De Monasterio and Gouras, 1975; de Monasterio, 1978a; Smith et al., 1992; Yeh et al., 1995; Lee et al., 2000; Solomon et al., 2005; Tailby et al., 2008). The spatially comparable S-ON and LM-OFF fields of the blue-ON cell contrast sharply with the classic center-surround receptive field structure of the other two common LGN-projecting ganglion cells of the primate-the midget and parasol cells (Derrington and Lennie, 1984; Croner and Kaplan, 1995; White et al., 2001), where surrounds are about fifty times the area of but 100 times less sensitive (per unit area) than the center and the integrated sensitivity (peak sensitivity $X$ collecting area) is only about half that of the center. Consequently, the center response dominates even for stimuli that encompass the much larger surround (Croner and Kaplan, 1995). For the blue-ON cells, the opposing fields were comparable both in area and peak sensitivity (Fig. 6, Table 1), so that stimuli approximating the size of the dendritic tree can drive both S-ON and LM-OFF responses equally. There is a tendency for the LMOFF field to be on average slightly larger than the S-ON field $(\mathrm{S}: \mathrm{LM}=0.92 \pm 0.15 ; n=55)$ and a similar result was reported using the intact, anesthetized animal (Solomon et al., 2005). Another recent study using multielectrode recordings from the isolated, in vitro retina reported the LM field to be on average $48 \%$ larger ( $\sim 2$ times the area) than the $S$ field and concluded that the blue-ON cells showed a classic center-surround organization (Field et al., 2007). Field et al. (2007) did not report the relative sensitivities of the $\mathrm{S}$ versus the LM fields or construct a centersurround spatial receptive field model, so it is difficult to assess this data further in relation to our own. It is possible that eccen- tricity dependent changes in blue-ON receptive field structure could reconcile differences across studies. In the present and previous results coextensive S versus LM fields in either the LGN or retina of blue-ON cells were recorded within the central 20 degrees ( $<4 \mathrm{~mm}$ eccentricity). In contrast, the data in Field et al. (2007) were collected in the far retinal periphery (30-75 degrees eccentricity). Chromatic sensitivity in human vision declines significantly in the far periphery (Mullen, 1991; Mullen and Kingdom, 1996; Sakurai and Mullen, 2006). Whether blue-ON cells show reduced chromatic and/or increased achromatic sensitivity in the retinal periphery remains to be determined.

\section{OFF cone bipolar origin for the LM field}

Sparing of the LM OFF response after L-AP-4 application is consistent with OFF bipolar synaptic input to the distinct outer dendritic arbor of the small bistratified cell (Fig. 1) (Calkins et al., 1998; Ghosh and Grünert, 1999). Our results appear inconsistent with a reported total loss of the blue-ON cell light response and maintained discharge in the presence of L-AP-4 (Field et al., 2007). We would argue caution in interpreting these results. The action of L-AP-4 on mGluR6 mimics tonic glutamate release and hyperpolarizes the ON bipolar cell (Awatramani and Slaughter, 2001) and subsequently the ON ganglion cell (Zaghloul et al., 2003; Davenport, 2007; Margolis and Detwiler, 2007). Thus, if L-AP-4 hyperpolarizes the blue-ON cell the LM OFF input may not drive the membrane potential to spike threshold. Our recordings were made in the RPE-choroid-attached retina and permitted stimulation at high photopic levels. Under these conditions maintained discharge and the LM-OFF response were consistently spared after bath application of L-AP-4.

Failure of picrotoxin and/or strychnine to significantly modify the S ON or LM OFF response amplitude was also consistent with an excitatory cone bipolar origin for the LM OFF field, and we suggest that amacrine circuitry is not critical for generating $S$ versus LM cone opponency. The majority of synaptic inputs to the small bistratified cell are from amacrine cells, however (Ghosh and Grünert, 1999), so the significance of these inputs remains open. There is strong evidence that inner retinal inhibition to some extent works in a push-pull manner to reinforce excitation, and that the OFF pathway, at least for certain ganglion cell types, receives more inhibition from the ON pathway than vice versa (Pang et al., 2003; Zaghloul et al., 2003; Murphy and Rieke, 2006; Margolis and Detwiler, 2007; Molnar and Werblin, 2007; Manookin et al., 2008). It seems unlikely that the S-ON bipolar would drive such "cross-pathway" amacrine inhibition to the LM-OFF bipolar as this would work against the basic cone opponent response in which S increments reinforce LM decrements. It is possible, however, that disinhibition that arises in LM ON cone bipolar cells reinforces the LM OFF response-although at the high photopic levels and moderate contrasts used here we did not observe a change in the LM OFF response relative to the $\mathrm{S}$ ON response after inhibitory block (Fig. 7). Whole-cell recordings of blue-ON cells under voltage clamp designed to measure the phase and amplitude of excitatory and inhibitory conductances generated by $S$ and LM selective stimuli are required to directly address this question.

A striking but consistent effect of L-AP-4 was the dramatic change in the LM-OFF response to bandpass spatial frequency tuning that could be fit with a center-surround receptive field model (Fig. 8). This center-surround structure was maintained during block of inhibition but was attenuated by increasing retinal buffering capacity with HEPES (Fig. 9). Surround reduction by HEPES buffering has been described in nonmammalian retina 
and it has been suggested that HEPES acts on a protondependent, non-GABAergic horizontal to cone feedback pathway (Hirasawa and Kaneko, 2003; Vessey et al., 2005; Cadetti and Thoreson, 2006). The surrounds of parasol ganglion cells are also maintained after block of retinal inhibition (McMahon et al., 2004) but attenuated by HEPES (Davenport et al., 2008). We suggest therefore that L-AP-4 unmasks the basic center-surround structure of the LM-OFF bipolar input to the blue-ON cell, consistent with the presence of surrounds in cone bipolar cells (Dacey et al., 2000b). What underlies the unmasking of this basic center-surround structure by L-AP-4? We hypothesize that the $\mathrm{S}-\mathrm{ON}$ bipolar cell also possesses an LM OFF surround and that under conditions where S-ON and LM-OFF fields are functioning, there is no or little net surround antagonism (Fig. 10). The LM-OFF surround of the S-ON bipolar would arise by feedback from $\mathrm{H} 2$ horizontal cells, whose processes contact $\mathrm{S}$, L, and $\mathrm{M}$ cones. The LM-ON surround of the LM-OFF bipolar would arise by feedback from the $\mathrm{H} 1$ horizontal cell that contacts $\mathrm{L}$ and $\mathrm{M}$ cones nonselectively (Dacey et al., 1996; Goodchild et al., 1996). The light response of the blue-cone bipolar cell (Kouyama and Marshak, 1992) is unknown. However, the S cone already possesses a large opponent surround driven by $\mathrm{L}$ and $\mathrm{M}$ cones (Packer et al., 2007) that is likely transmitted to the S-ON bipolar and in turn to the small bistratified ganglion cell.

\section{References}

Awatramani GB, Slaughter MM (2001) Intensity-dependent, rapid activation of presynaptic metabotropic glutamate receptors at a central synapse. J Neurosci 21:741-749.

Baylor DA, Lamb TD, Yau KW (1979) Responses of retinal rods to single photons. J Physiol 288:613-634.

Baylor DA, Nunn BJ, Schnapf JL (1984) The photocurrent, noise and spectral sensitivity of rods of the monkey Macaca fascicularis. J Physiol 357:575-607.

Baylor DA, Nunn BJ, Schnapf JL (1987) Spectral sensitivity of cones of the monkey Macaca fascicularis. J Physiol 390:145-160.

Buck SL (2004) Rod-cone interactions in human vision. In: The visual neurosciences (Chalupa LM, Werner JS, eds), pp 863-878. Cambridge, MA: MIT.

Cadetti L, Thoreson WB (2006) Feedback effects of horizontal cell membrane potential on cone calcium currents studied with simultaneous recordings. J Neurophysiol 95:1992-1995.

Calkins DJ, Tsukamoto Y, Sterling P (1998) Microcircuitry and mosaic of a blue-yellow ganglion cell in the primate retina. J Neurosci 18:3373-3385.

Croner LJ, Kaplan E (1995) Receptive fields of P and M ganglion cells across the primate retina. Vision Res 35:7-24.

Crook JD, Peterson BB, Packer OS, Robinson FR, Troy JB, Dacey DM (2008) $\mathrm{Y}$-cell receptive field and collicular projection of parasol ganglion cells in macaque monkey retina. J Neurosci 28:11277-11291.

Dacey DM (1993) Morphology of a small-field bistratified ganglion cell type in the macaque and human retina. Vis Neurosci 10:1081-1098.

Dacey DM (1996) Circuitry for color coding in the primate retina. Proc Natl Acad Sci U S A 93:582-588.

Dacey DM (2000) Parallel pathways for spectral coding in primate retina. Annu Rev Neurosci 23:743-775.

Dacey DM, Lee BB (1994) The blue-ON opponent pathway in primate retina originates from a distinct bistratified ganglion cell type. Nature 367:731-735.

Dacey DM, Packer OS (2003) Colour coding in the primate retina: diverse cell types and cone-specific circuitry. Curr Opin Neurobiol 13:421-427.

Dacey DM, Lee BB, Stafford DK, Pokorny J, Smith VC (1996) Horizontal cells of the primate retina: cone specificity without spectral opponency. Science 271:656-659.

Dacey DM, Diller LC, Verweij J, Williams DR (2000a) Physiology of L- and $\mathrm{M}$-cone inputs to $\mathrm{H} 1$ horizontal cells in the primate retina. J Opt Soc Am A Opt Image Sci Vis 17:589-596.

Dacey DM, Packer OS, Diller L, Brainard D, Peterson B, Lee B (2000b) Center surround receptive field structure of cone bipolar cells in primate retina. Vision Res 40:1801-1811.
Dacey DM, Liao HW, Peterson BB, Robinson FR, Smith VC, Pokorny J, Yau KW, Gamlin PD (2005) Melanopsin-expressing ganglion cells in primate retina signal colour and irradiance and project to the LGN. Nature 433:749-754.

Dartnall HJA (1972) Photosensitivity. In: Photochemistry of vision (Dartnall HJA, ed), pp 122-145. New York: Springer.

Davenport CM, Detwiler PB, Dacey DM (2008) Effects of pH buffering on horizontal and ganglion cell light responses in primate retina: evidence for the proton hypothesis of surround formation. J Neurosci 28:456-464.

Davenport CM (2007) Neural circuitry of retinal receptive fields in primate. $\mathrm{PhD}$ thesis, University of Washington.

de Monasterio FM (1978a) Properties of ganglion cells with atypical receptive-field organization in retina of macaques. J Neurophysiol 41:1435-1449.

de Monasterio FM (1978b) Center and surround mechanisms of opponentcolor X and Y ganglion cells of retina of macaques. J Neurophysiol 41:1418-1434.

De Monasterio FM, Gouras P (1975) Functional properties of ganglion cells of the rhesus monkey retina. J Physiol 251:167-195.

Derrington AM, Lennie P (1984) Spatial and temporal contrast sensitivities of neurones in lateral geniculate nucleus of macaque. J Physiol 357:219-240.

Derrington AM, Krauskopf J, Lennie P (1984) Chromatic mechanisms in lateral geniculate nucleus of macaque. J Physiol 357:241-265.

Diller L, Packer OS, Verweij J, McMahon MJ, Williams DR, Dacey DM (2004) L and $\mathrm{M}$ cone contributions to the midget and parasol ganglion cell receptive fields of macaque monkey retina. J Neurosci 24:1079-1088.

Dreher B, Fukada Y, Rodieck RW (1976) Identification, classification and anatomical segregation of cells with X-like and Y-like properties in the lateral geniculate nucleus of old-world primates. J Physiol 258:433-452.

Enroth-Cugell C, Hertz BG, Lennie P (1977) Convergence of rod and cone signals in the cat's retina. J Physiol 269:297-318.

Enroth-Cugell C, Robson JG, Schweitzer-Tong DE, Watson AB (1983) Spatio-temporal interactions in cat retinal ganglion cells showing linear spatial summation. J Physiol 341:279-307.

Estévez O, Spekreijse H (1974) A spectral compensation method for determining the flicker characteristics of the human colour mechanisms. Vision Res 14:823-830.

Estévez O, Spekreijse H (1982) The "silent substitution" method in visual research. Vision Res 22:681-691.

Famiglietti EV Jr, Kolb H (1975) A bistratified amacrine cell and synaptic circuitry in the inner plexiform layer of the retina. Brain Res 84:293-300.

Field GD, Sher A, Gauthier JL, Greschner M, Shlens J, Litke AM, Chichilnisky EJ (2007) Spatial properties and functional organization of small bistratified ganglion cells in primate retina. J Neurosci 27:13261-13272.

Frishman LJ, Freeman AW, Troy JB, Schweitzer-Tong DE, Enroth-Cugell C (1987) Spatiotemporal frequency responses of cat retinal ganglion cells. J Gen Physiol 89:599-628.

Ghosh KK, Grünert U (1999) Synaptic input to small bistratified (blue-ON) ganglion cells in the retina of a new world monkey, the marmoset Callithrix jacchus. J Comp Neurol 413:417-428.

Ghosh KK, Martin PR, Grünert U (1997) Morphological analysis of the blue cone pathway in the retina of a new world monkey, the marmoset Callithrix jacchus. J Comp Neurol 379:211-225.

Goodchild AK, Chan TL, Grünert U (1996) Horizontal cell connections with short-wavelength-sensitive cones in macaque monkey retina. Vis Neurosci 13:833-845.

Gouras P (1967) The effects of light adaptation on rod and cone receptive field organization of monkey ganglion cells. J Physiol 192:747-760.

Gouras P, Link K (1966) Rod and cone interaction in dark-adapted monkey ganglion cells. J Physiol 184:499-510.

Gouras P, Zrenner E (1979) Enhancement of luminance flicker by coloropponent mechanisms. Science 205:587-589.

Hayhoe MM, MacLeod DIA, Bruch TA (1976) Rod-cone independence in dark adaptation. Vision Res 16:591-600.

Hirasawa H, Kaneko A (2003) pH changes in the invaginating synaptic cleft mediate feedback from horizontal cells to cone photoreceptors by modulating Ca2+ channels. J Gen Physiol 122:657-671.

Kamermans M, Fahrenfort I (2004) Ephaptic interactions within a chemical synapse: hemichannel-mediated ephaptic inhibition in the retina. Curr Opin Neurobiol 14:531-541. 
Kamermans M, Spekreijse H (1999) The feedback pathway from horizontal cells to cones - a mini review with a look ahead. Vision Res 39:2449-2468.

Kouyama N, Marshak DW (1992) Bipolar cells specific for blue cones in the macaque retina. J Neurosci 12:1233-1252.

Lee BB, Smith VC, Pokorny J, Kremers J (1997) Rod inputs to macaque ganglion cells. Vision Res 37:2813-2828.

Lee BB, Silveira LC, Yamada ES, Hunt DM, Kremers J, Martin PR, Troy JB, da Silva-Filho M (2000) Visual responses of ganglion cells of a New-World primate, the capuchin monkey, Cebus apella. J Physiol 528:573-590.

Lennie P, Movshon JA (2005) Coding of color and form in the geniculostriate visual pathway (invited review). J Opt Soc Am A Opt Image Sci Vis 22:2013-2033.

Manookin MB, Beaudoin DL, Ernst ZR, Flagel LJ, Demb JB (2008) Disinhibition combines with excitation to extend the operating range of the OFF visual pathway in daylight. J Neurosci 28:4136-4150.

Margolis DJ, Detwiler PB (2007) Different mechanisms generate maintained activity in $\mathrm{ON}$ and OFF retinal ganglion cells. J Neurosci 27:5994-6005.

Marshak DW, Rangal C, O’Brien J (2009) Gap junctions between AII amacrine cells and blue cone bipolar cells in macaque retina. Paper presented at The Association for Research in Vision and Ophthalmology 2009 Annual Meeting, Fort Lauderdale, FL, May.

McMahon MJ, Packer OS, Dacey DM (2004) The classical receptive field surround of primate parasol ganglion cells is mediated primarily by a non-GABAergic pathway. J Neurosci 24:3736-3745.

Molnar A, Werblin F (2007) Inhibitory feedback shapes bipolar cell responses in the rabbit retina. J Neurophysiol 98:3423-3435.

Mullen KT (1991) Colour vision as a post-receptoral specialization of the central visual field. Vision Res 31:119-130.

Mullen KT, Kingdom FAA (1996) Losses in peripheral colour sensitivity predicted from "hit and miss" post-receptoral cone connections. Vision Res 36:1995-2000.

Müller F, Wässle H, Voigt T (1988) Pharmacological modulation of the rod pathway in the cat retina. J Neurophysiol 59:1657-1672.

Murphy GJ, Rieke F (2006) Network variability limits stimulus-evoked spike timing precision in retinal ganglion cells. Neuron 52:511-524.

Packer O, Verweij J, Schnapf J, Dacey D (2007) Primate S cones have blueyellow opponent receptive fields. Paper presented at The Association for Research in Vision and Ophthalmology 2007 Annual Meeting, Fort Lauderdale, FL, May.

Packer OS, Williams DR, Bensinger DG (1996) Photopigment transmittance imaging of the primate photoreceptor mosaic. J Neurosci 16:2251-2260.

Pang JJ, Gao F, Wu SM (2003) Light-evoked excitatory and inhibitory synaptic inputs to $\mathrm{ON}$ and $\mathrm{OFF}$ alpha ganglion cells in the mouse retina. J Neurosci 23:6063-6073.

Petrides A, Trexler EB (2008) Differential output of the high-sensitivity rod photoreceptor: AII amacrine pathway. J Comp Neurol 507:1653-1662.

Pokorny J, Smithson H, Quinlan J (2004) Photostimulator allowing independent control of rods and the three cone types. Vis Neurosci 21:263267.
Reid RC, Shapley RM (1992) Spatial structure of cone inputs to receptive fields in primate lateral geniculate nucleus. Nature 356:716-718.

Reid RC, Shapley RM (2002) Space and time maps of cone photoreceptor signals in macaque lateral geniculate nucleus. J Neurosci 22:6158-6175.

Rodieck RW (1991) Which cells code for color? In: From pigments to perception (Valberg A, Lee BB, eds), pp 83-93. New York: Plenum.

Sakurai M, Mullen KT (2006) Cone weights for the two cone-opponent systems in peripheral vision and asymmetries of cone contrast sensitivity. Vision Res 46:4346-4354.

Schein S, Sterling P, Ngo IT, Huang TM, Herr S (2004) Evidence that each S cone in macaque fovea drives one narrow-field and several wide-field blue-yellow ganglion cells. J Neurosci 24:8366-8378.

Schein SJ (1988) Anatomy of macaque fovea and spatial densities of neurons in foveal representation. J Comp Neurol 269:479-505.

Slaughter MM, Miller RF (1981) 2-Amino-4-phosphonobutyric acid: a new pharmacological tool for retina research. Science 211:182-185.

Smith VC, Lee BB, Pokorny J, Martin PR, Valberg A (1992) Responses of macaque ganglion cells to the relative phase of heterochromatically modulated lights. J Physiol 458:191-221.

Solomon SG, Lennie P (2007) The machinery of colour vision. Nat Rev Neurosci 8:276-286.

Solomon SG, Lee BB, White AJ, Rüttiger L, Martin PR (2005) Chromatic organization of ganglion cell receptive fields in the peripheral retina. J Neurosci 25:4527-4539.

Strettoi E, Raviola E, Dacheux RF (1992) Synaptic connections of the narrow-field, bistratified rod amacrine cell (AII) in the rabbit retina. J Comp Neurol 325:152-168.

Tailby C, Solomon SG, Lennie P (2008) Functional asymmetries in visual pathways carrying S-cone signals in macaque. J Neurosci 28:4078-4087.

Vessey JP, Stratis AK, Daniels BA, Da Silva N, Jonz MG, Lalonde MR, Baldridge WH, Barnes S (2005) Proton-mediated feedback inhibition of presynaptic calcium channels at the cone photoreceptor synapse. J Neurosci 25:4108-4117.

Virsu V, Lee BB, Creutzfeldt OD (1987) Mesopic spectral responses and the purkinje shift of macaque lateral geniculate nucleus cells. Vision Res 27:191-200.

Völgyi B, Deans MR, Paul DL, Bloomfield SA (2004) Convergence and segregation of the multiple rod pathways in mammalian retina. J Neurosci 24:11182-11192.

White AJ, Solomon SG, Martin PR (2001) Spatial properties of koniocellular cells in the lateral geniculate nucleus of the marmoset Callithrix jacchus. J Physiol 533:519-535.

Wiesel TN, Hubel DH (1966) Spatial and chromatic interactions in the lateral geniculate body of the rhesus monkey. J Neurophysiol 29:1115-1156.

Yeh T, Lee BB, Kremers J (1995) The temporal response of ganglion cells of the macaque retina to cone-specific modulation. J Opt Soc Am A Opt Image Sci Vis 12:456-464.

Zaghloul KA, Boahen K, Demb JB (2003) Different circuits for ON and OFF retinal ganglion cells cause different contrast sensitivities. J Neurosci 23: 2645-2654. 